\title{
Performative Achievement of Routine Recognizability: An Analysis of Order Taking Routines at Sushi Bars
}

\author{
$\operatorname{AUTHOR(S):~}$
}

Yamauchi, Yutaka; Hiramoto, Takeshi

\section{CITATION:}

Yamauchi, Yutaka ... [et al]. Performative Achievement of Routine Recognizability: An Analysis of Order Taking Routines at Sushi Bars. Journal of Management Studies 2020, 57(8): 1610-1642

ISSUE DATE:

2020-12

URL:

http://hdl.handle.net/2433/259228

\section{RIGHT:}

This is the peer reviewed version of the following article: 'Journal of Management Studies', 57(8), 1610-1642], which has been published in final form at https://doi.org/10.1111/joms.12555. This article may be used for non-commercial purposes in accordance with Wiley Terms and Conditions for Use of Self-Archived Versions.; The full-text file will be made open to the public on 17 February 2022 in accordance with publisher's 'Terms and Conditions for Self-Archiving', この論文は出版社版でありません。引用の際には出版社版をご確認ご利用ください。; This is not the published version. Please cite only the published version. 


\title{
Performative Achievement of Routine Recognizability: An Analysis of Order Taking Routines at Sushi Bars
}

\author{
Yutaka Yamauchi \\ Graduate School of Management, Kyoto University \\ yamauchi@gsm.kyoto-u.ac.jp \\ Takeshi Hiramoto \\ Kyoto Washoku Institute, \\ Kyoto Prefectural University \\ hiramoto@kpu.ac.jp
}

\begin{abstract}
The concept of performativity, a central theme in routine dynamics research, suggests that a routine does not first exist as a recognizable phenomenon, and then actions are taken subsequently. On the contrary, actions themselves need to achieve the recognizability of the routine. This paper revisits recognizability in light of routine interdependence and materiality. Focusing on order taking routines at sushi bars, the analysis reveals that participants constantly achieve the beginning of a routine performance by drawing on performances of other routines and materiality, both of which are seemingly unrelated to the focal routine. Prior to routine initiation, much material and embodied work is conducted in order to make the routine recognizable. Once initiated, the routine performance makes subtle use of materiality, allowing participants to engage in a seemingly unrelated routine while they remain subordinately attentive to the focal routine. While a routine appears to exist on its own once it is recognized, the achievement of this recognition relies largely on factors that are not part of the routine.
\end{abstract}

Keywords: Routines, ethnomethodology, performativity, reflexivity, materiality 


\section{INTRODUCTION}

How is a routine performance recognized as that of a particular routine? Routines are generally defined as "repetitive, recognizable patterns of interdependent actions, carried out by multiple actors" (Feldman and Pentland, 2003, p. 95). This research primarily focuses on the issue of recognizability within this definition. A routine does not first recognizably exist, and then actions are taken subsequently; the actions themselves need to achieve the recognizability of the routine. Traditionally routines have been treated as "things" (Feldman, Pentland, D'Adderio, and Lazaric, 2016) that are readily recognizable. However, recent research on routine dynamics has criticized this view of routines as "things" and explored how routines are enacted through actions in concrete situations (Becker, 2008; D'Adderio, 2008; 2014; Feldman, 2000; Feldman and Pentland, 2003; Howard-Grenville, Rerup, Langley, and Tsoukas, 2016; Parmigiani and Howard-Grenville, 2011; Turner and Rindova, 2012).

This recognizability is particularly critical at the beginning of a routine performance. When the routine performance has not begun, recognizability does not yet exist-it needs to be created. Pentland and Feldman pointed out that "Identifying a particular routine is a bit like trying to isolate the Gulf Stream from the Atlantic Ocean. Identification is part of the act of creation... It is not always obvious where a particular routine begins or ends" (Pentland and Feldman, 2005, p. 798). Therefore, we must understand how actions make themselves recognizable and identifiable (Feldman, 2016). Recognizability, as we conceive it in this study, encompasses the entire process through which actions establish a recognizable pattern, including not only the initiating action but also the alignment of actions into such a pattern. A person cannot simply start a routine performance. Rather, this individual needs to coordinate with others to align the actions of all involved parties so that the pattern of actions is recognizable as routine.

For example, take a situation familiar to many readers: an instructor enters a classroom where students are engaged in other activities such as talking with classmates, texting, or having a quick snack. Then, the time comes to start the class. How can the routine of classroom instruction be initiated? The time on the clock may be a trigger, but the instructor still needs to do something to let the students know the class is about to start. The instructor might say, "Hello everyone, let's get started." However, a statement like this might be drowned out by the noise of the other students talking. Furthermore, many of the students who have been engaged in ongoing activities may not be ready to pay attention to the instructor and require a moment to orient themselves to the class, e.g., putting a phone aside, throwing away trash, and returning to one's own seat. The instructor might open a textbook or set up a computer while waiting, but also monitor the students in order to judge when to proceed. After all the physical elements (computers, textbooks, clock) as well as the participants (students, instructor) are aligned, the instructor can begin the class.

In this manner, recognizability of a routine is achieved through a sequence of coordinated actions by multiple participants (Pentland, 1995; Pentland, Feldman, Becker, and Liu, 2012). To address the question of sequentially achieved recognizability, ethnomethodology (Garfinkel, 1967) and the related field of conversation analysis (Sacks, 1995; Schegloff, 2007) provide both a useful perspective and methodology. Ethnomethodology seeks to understand how mundane routine activities are achieved through intricate coordination among multiple actors (Heath, Hindmarsh, and Luff, 2010; Llewellyn and Hindmarsh, 2010; Schegloff, 1986). To this end, ethnomethodology pays particular attention to recognizability, or "accountability" as originally defined (Garfinkel, 1967). The central tenet of ethnomethodology aims at understanding how participants account for an action, as well as how they produce the action. Therefore, we can use ethnomethodology to analyze in detail how involved parties achieve recognizable patterns of actions through a sequence of coordinated actions (LeBaron, Christianson, Garrett, and Ilan, 2016; Yamauchi and Hiramoto, 2016).

In this study, we use a restaurant setting, specifically sushi bars in Tokyo. There are various routines in a restaurant such as ordering, food preparation, and eating which, in these types of sushi establishments, are repeated many times during the course of a meal. Among these various routines, one particular routine-order taking-is particularly interesting because it involves an economic contract between a customer and a restaurant; the customer is bound to pay for the item that she orders, and the restaurant is bound to deliver it. Therefore, this routine needs to be "framed" (Callon, 1998; 2013) in a standard manner, clearly demarcated from other activities. This standard routine needs to initiate itself while other routines are ongoing, e.g., customers may be eating and chatting, and chefs may be preparing various items. Specifically, the routine needs to terminate, interrupt, divert 
or otherwise reshape these other routines. Furthermore, multiple parties, namely the chef and the customer need to take their parts to achieve the ordering; the customer needs to specify an item to order and the chef needs to accept and register the order. Therefore, this order taking routine offers a useful opportunity to investigate routine recognizability.

Empirical analysis shows much work is needed to construct the situation so that a routine performance can initiate itself. To achieve the routine's recognizability, the routine performance intertwines what is seemingly unrelated to the focal routine as well as what is pertinent to it. The routine is not closed; it can achieve its own boundary only by intermixing other seemingly unrelated routine performances and materiality within itself. This insight helps advance the relational nature of routine performativity and expands our understanding of materiality.

\section{PERFORMATIVE RECOGNIZABILITY OF ROUTINES}

\section{Performativity of Routines}

Literature on routine dynamics has advanced the concept of routines significantly by emphasizing the actions that constitute routines. Routines are not static entities but are performatively achieved through actions situated in a concrete context (Feldman and Pentland, 2003; Parmigiani and HowardGrenville, 2011). Performativity means that a routine does not first exist and is subsequently executed; the situated actions enact the routine. Even when a routine appears to be stable, actual performance varies, and in fact it is the varied performance that achieves the stability of routines (Aroles and McLean, 2016; D'Adderio, 2014; Howard-Grenville, 2005; Turner and Rindova, 2012). While a routine appears to be a simple repetition of the same, each performance of a routine is an effortful accomplishment (Pentland and Rueter, 1994).

At the same time, routines do not consist of arbitrary actions; the actions exhibit certain patterns, often called "ostensive aspects" of a routine (Feldman and Pentland, 2003), so that these actions can be recognized as part of a particular routine. Their original distinction of ostensive and performative aspects of routines was intended not only to explain flexibility of routines through performative aspects but also to explain recognizability of the ostensive patterning of routines (Feldman, 2016).

Ostensive aspects refer to patterning of actions recognizable as a particular routine and not to cognitive understandings that people have about a routine detached from actions. To advance this view, Feldman (2016) made a further call for "making action more focal in our study of routines" (p. 38). She wrote,

What we need, instead, is to explore the specific actions (doings and sayings) involved in creating patterns or patterning. How do we create recognizability? The relevant question is "How do we do patterning?" (p. 39).

This study answers Feldman's call and examines how a sequence of actions makes itself recognizable as a patterned activity of a particular routine. Feldman (2016) wrote, "performing routines involves orienting to patterns (conceptualized as ostensive aspects)" (p. 37); therefore, "emphasizing the constitutive nature of action in the process of patterning draws our attention to the work of recognizing and articulating or narrating these patterns" (p. 40). This "work" of recognizing patterns needs to be explained. LeBaron, Christianson, Garrett, and Ilan (2016), in concluding their ethnomethodological study of routine performances, wrote, "Regarding mutual intelligibility as something that participants perform and display helps to deepen our appreciation of routines as effortful accomplishments: participants not only assemble a sequence of moves from a repertoire of possible moves (Pentland and Rueter, 1994), but they also engage in real-time adjustment to make the enactment of those moves mutually intelligible" (p. 531). Recognizability, or mutual intelligibility, is not presumed, but rather achieved through actions.

This recognizability is particularly critical when a routine performance begins. There is no predetermined space in which a routine can begin. The performance needs to create the space where it can be initiated. In other words, a sequence of actions initiating a routine are not automatically part of a routine but need to make themselves recognizable as constituting that particular patterned activity. Furthermore, one single action to initiate a routine performance, e.g., the instructor's utterance "Let's get started," is not sufficient to achieve the beginning of classroom instruction; the beginning of a routine performance encompasses not just the initiating action but also a sequence of multiple actions 
that achieve the alignment.

\section{Interrelatedness and Materiality in Routine Performance}

The performative view no longer allows us to consider a routine in isolation. Routine performances are always embedded in the interrelations with other routine performances as well as the material and embodied situations. Scholars now examine interrelated routines and their ecologies (Birnholtz, Cohen, and Hoch, 2007; Kremser and Schreyögg, 2016; Spee, Jarzabkowski, and Smets, 2016). Routine dynamics is said to result not only from the situated repetitive performances of a single routine but also from interactions among multiple routines (Spee et al., 2016). The dynamics of routines need to be understood at the level of ecology or that of a cluster because how a single routine fits in the interrelation of routines is a key part of the dynamic (Birnholtz et al., 2007; Kremser and Schreyögg, 2016). At the same time, a routine can also generate innovations by reshaping relationships among routines (Sele and Grand, 2016).

This interrelation is vital for recognizability. In that a routine is not a phenomenon with a clearly given boundary, a routine performance needs to create its own recognizability by demarcating itself from other ongoing routine performances. When a routine performance begins, there are often many other ongoing activities that need to be terminated, paused, or otherwise sidestepped. The routine performance does not first unfold in isolation and then become related to other routine performances. When another routine intersects with a focal routine, we must start analysis not with two separate routines but with actions that make themselves recognizable as part of a particular pattern of action by relating to each other. Our first question then is how recognizability of the performance of a focal routine is created out of this interrelation with other routine performances.

Although scholars have emphasized the achieved nature of routine interrelatedness by analyzing situated micro dynamics (Birnholtz et al., 2007; Kremser and Schreyögg, 2016; Sele and Grand, 2016; Spee et al., 2016; Turner and Rindova, 2012), the question of recognizability has not been sufficiently explored. Scholars have sought to direct attention to how these interactions take place among routines and placed less emphasis on how each of the routine performances comes to be recognized. On the other hand, the empirical research on routine recognizability (LeBaron et al., 2016; Yamauchi and Hiramoto, 2016) has not paid much attention to relationships with other routines; the focus was on examining in detail the sequential organization within a single routine. As there is now sufficient work examining routine interrelatedness, we can revisit routine recognizability.

Another key theme in routine dynamics is materiality. Knowledge and skills are inscribed in and distributed across artifacts as much as they are possessed by humans (Pentland et al., 2012). Artifacts such as procedures, rules, and tools mediate routine performance to facilitate standardization or flexibility (D'Adderio, 2011; 2014; Spee et al., 2016; Turner and Rindova, 2012). Bodies and movements, such as gestures, gazes, and postures, are also critical part of materiality (LeBaron et al., 2016). Furthermore, the concept of materiality is invoked to shift the focus from human subjects to social and material assemblage. Assemblage refers to the complex of heterogeneous elements including humans and non-humans, which function together without reducing any of these elements into the others (Callon, 2013; Deleuze and Guattari, 2013). D'Adderio (2008; 2011; 2014) advanced this concept of materiality for routine research. The agency does not reside in human actors but is "stretched across" heterogeneous elements including humans, objects, and artifacts (D'Adderio, 2011, p. 210). We now decenter human subjects, which were traditionally seen to have privilege in shaping and carrying out routines, and instead examine how actions are made possible by the sociomaterial assemblage of which humans are only part (Aroles and McLean, 2016; Callon, 2013; D'Adderio, 2008; 2011; Glaser, 2017; Glaser, Fiss, and Kennedy, 2016; Latour, 2005; Orlikowski and Scott, 2008).

Materiality is important in terms of recognizability because a routine performance is always enacted through the material and embodied context. A routine performance cannot simply begin and unfold in a vacuum. While it is shaped by a particular sociomaterial context, it also needs to renew the context so that it can achieve its own recognizability and form a recognizable pattern of action (Emirbayer and Mische, 1998; Heritage, 1984). In other words, we build on D'Adderio (2014, p. 1347), who wrote "routines are not simply embedded in context, they are also enacted through context" (emphasis in original). We cannot start classroom instruction without elements of the classroom, such as the time shown on the clock and the bodily presence of the instructor, being properly aligned. At the same time, the routine performance needs to assemble these material elements by shaping, making relevant, and assigning situated meanings to them while simultaneously excluding other elements. The second 
research question then is how recognizability of the performance of a focal routine is created out of the sociomaterial context.

In relation to materiality the question of recognizability has been underexplored. Prior routine dynamics research has discussed how routines that are already recognized interact with artifacts. These artifacts are also already recognized, although it is acknowledged that their meanings and shapes change as routines are enacted with multiple actors (D'Adderio, 2008; 2011; 2014; Glaser, 2017; Turner and Rindova, 2012). This acknowledgement was a necessary move in order to treat materiality on a footing equal to humans, that is to say, not to rely on humans giving meaning to materiality. As recently we have gained a greater understanding of materiality, we now must address the issue of recognizability in relation to materiality. A routine performance cannot abruptly begin, but rather it needs to create an assemblage in which it can make itself recognizable as a certain patterned activity. To understand how recognizability is created, we need to analyze how material objects and bodies are assembled preceding the routine itself when they are not yet part of the routine. Therefore, we cannot begin an analysis with the routine and then discuss the relevance of materiality. We need to begin the analysis with materiality in order to explain how the routine comes to be recognized.

\section{An Ethnomethodological Perspective}

Ethnomethodology is particularly effective for analyzing recognizability. The premise of ethnomethodology is to seek the recognizability, or accountability in ethnomethodological terms, within the participants' own actions, not to provide interpretation as an external analyst (Garfinkel, 1967). When an individual wants to start a routine, he or she cannot simply do this anytime or anywhere; this person needs to choose the right situation and organize a sequence of actions to do so. In other words, she needs to account for her own actions while carrying out these actions. For instance, research in ethnomethodology and conversation analysis has shown that the initiation of a conversation is achieved in a fluid manner. One does not simply start speaking; the participants need to mutually align their attention and establish availability to a conversation. In describing how people come into a conversation, Schegloff (1968) showed that a summons-answer sequence acts as a special device for achieving this mutual alignment: One issues a summons (e.g., "Jim?" and "Mommy?"), which obliges the other person to answer, making a lack of answer noticeable and problematic. In the case of phone conversations, Schegloff showed that even prior to the initial talk, the summons has already begun; namely, the phone ringing is a summons. What the recipient has been doing, even prior to the ringing, is relevant; for instance, a particularly long ringing indicates that the recipient might be engaged in some other activity. When the recipient picks up, the initiation of the conversation was then coordinated with the prior activity.

This fluid beginning has greater nuance in cases of face-to-face conversations where materiality and bodies are explicitly relevant. For instance, Mondada (2009) examined the way in which people stop strangers in a public space to ask for directions. An inquirer will walk toward and glance at a passerby while producing an utterance such as "ehm", and the passer-by then turns his gaze to the inquirer. In the meantime, the passer-by may sometimes twist his torso, dividing his direction between his original walking trajectory and facing the inquirer. The passer-by, while still walking, then stops when the inquirer gives the reason why she stopped him, i.e., asking for directions. Only then, can these two individuals engage in further conversation. The beginning of the conversation overlaps with the other activity of the passer-by, namely walking. The beginning of the conversation is then dynamically and fluidly achieved through a rather elaborate sequence in relation to other activities that are embodied. Bodies have been analyzed in this ethnomethodological tradition (Hindmarsh and Llewellyn, 2017; Hindmarsh and Pilnick, 2007). For instance, Goodwin (1980) demonstrated that gaze is critical in coordinating the beginnings of ordinary conversations: When one speaks by looking at one's conversation partner, the partner is obliged to direct gaze to the speaker. The speaker often restarts the talk by cutting off prior talk and starting a new utterance only after securing the recipient's gaze. The gaze therefore is an achieved matter, which simultaneously achieves the beginning of a conversation. A variety of material resources can be used in addition to the gaze. LeBaron et al. (2016) demonstrated that gestures of closing one's eyes and pinching one's nose, and turning of pages on a notebook were all coordinated to make the ongoing routine performance mutually intelligible (See also, Heath, 1984). Furthermore, in one study conducted at an electronics store, Clark and Pinch (2010) showed that customers as well as store personnel engage in a variety of actions to create the 
conditions under which personnel can speak to customers, e.g., by standing directly in front of certain merchandise and even picking up items by hand, therefore signaling approachability.

Building on these insights from studies of ordinary conversations, but not organizational routines, the present study examines how routine recognizability is achieved in interaction with other routines and with materiality and bodies. In summary, this study examines routine recognizability by engaging the two themes of routine interrelatedness and materiality.

\section{RESEARCH DESIGN}

\section{Research Setting}

We conducted research at traditional sushi bars in Tokyo, a setting that was chosen for two principal reasons. First, prior studies have shown that routines are important in customer interactions. For example, studies of organizational routines have discussed routines at organizational boundaries such as academic hiring (Feldman and Pentland, 2003), moving students into residence halls (Feldman, 2000), collecting waste from customers (Turner and Rindova, 2012), airline ticketing (Pentland and Feldman, 2007), and business-to-business pricing (Zbaracki and Bergen, 2010). Because individuals who are unfamiliar with an organization come into contact with the organization in these situations, routines are important to render interactions understandable and predictable (Leidner, 1993). This situation is particularly salient in the case of ordering routines in sushi bars because participants, namely the service provider and the customers, need to directly coordinate their actions within a short period of time.

The second reason for choosing sushi bars concerns the material configuration of these establishments. In traditional sushi bars, chefs and customers face each other directly and share the same space. Within that space, they enter into and exit from interactions frequently. Chefs take drink orders from customers and then return to previous activities such as preparing food. Customers are also engaged in various activities such as chatting with other customers and eating and drinking. The initiation of a routine performance requires coordination of these various other activities, and this type of coordination happens many times during the meal in these sushi bars, with each episode of coordination taking place in a short period of time. Thus, these establishments represent a very suitable setting in which to gather data.

At the outset, we began this study without specific focus on routines. Our initial analysis revealed that the chefs and customers repeatedly started and concluded similar types of interactions throughout a meal. Particularly, we observed many interactions of ordering, which were organized in a similar manner between the same set of a chef and customer (or group of customers), across different customers, and across different sushi bars. We also observed repetitions of food and drink delivery and of food preparation. These initial analyses led us to the conclusion that these activities were standard types that were repeated many times; hence we found the concept of routine to be a promising area for examination. Thereafter, we chose to focus on ordering routines because customers were highly involved, and much coordination was needed. In contrast, routines of food and drink delivery were largely unilateral; customers did not play much of a role; e.g., simply nodding to the chef's explanation of the food was often sufficient. Therefore, the coordination among involved parties in ordering routines offered the opportunity for more systematic analysis.

We have reported analysis based on the subset of the same data elsewhere (Yamauchi and Hiramoto, 2016). In addition to three sushi bars studied in our previous article, in the present paper we added data collected at a fourth sushi bar. The previous article focused on how chefs and customers achieved the ordering routine when customers did not necessarily have a full understanding of the routinethe analysis followed the interactions after the routine had begun. During the course of analysis, it became apparent that the beginning part of the routine performance was problematic. For instance, customers were often not immediately able to respond to a chef's order solicitation. We also observed various subtle embodied actions on the part of the chef when initiating the routine performance, suggesting that the beginning was not as straightforward as commonly thought. Hence, we chose to focus on beginnings separately in the present study.

Routines can be identified at different levels of granularity. The meal as a whole can be considered as a single routine, beginning with the entry to the establishment. In this study, we chose to treat activities such as order taking and food preparation as individual routines. While there is no reason to privilege one level over another, analysts are required to present the ground on which the chosen activity is 
characterized as a routine, for instance, by showing how participants themselves orient to a patterned, repetitive activity. In our case, there is a normative rule of an order taking routine that participants orient to-how this is done needs to be explained through the analysis below. At minimum, the customer is required to convey a specific item as an order for which she is committed to pay and the service provider needs to accept the order and to deliver the item. Participants orient to this normative rule. For instance, the chef cannot conclude the interaction but must wait while a customer specifies an item to order unless the customers explicitly state that they need more time to think or they do not want to eat any more-we can see that in these latter cases customers elaborate on their reasons for their lack of order placement (e.g., saying, "I cannot drink any more"). Customers act according to this rule to show an understanding that they need to specify an item to order-although the level of detail that needs to be specified is often unclear. Participants' own orientation to this normative rule shows that they are engaged not in some other activity but in the patterns of action recognizable as order taking.

All of the four sushi bars studied are designed in a traditional style where there is a long counter across which chefs face customers. The chefs prepare the food in front of customers, and customers eat in front of the chefs; drink preparation and some preparatory cooking are done behind the wall. Thus, unlike many other restaurants the customers directly convey their orders to the chefs. All four sushi bars are well known and have often been featured in books and magazines; they are all high-end; the typical bill for one person at these sushi bars ranged from 15,000 to 25,000 Japanese yen (roughly 125 to 210 USD). Two of the four sushi bars had an omakase system, where customers are given a predesigned course. The other two had an okonomi system, where customers choose one food item after another. Even in the omakase system, customers need to order drinks separately on an individual basis and also often order additional food items, i.e., sushi, after the course is finished; the course may also be altered if customers feel full before it is complete or would not like to eat some specific items. The analysis focuses on these ordering routines.

We had 11 customers (two singles, three couples, and one group of three) at the first sushi bar (hereafter called A), six (two singles and two couples) at B, seven (three singles and two couples) at C, and 11 (six singles and two couples) at D. We had 27 participants, of which 5 participated in multiple studies (some more than twice), resulting in 35 customers in total. There were three chefs at A, one at $B$, two at $C$, and one at $D$. We recruited customers who agreed to be videotaped and signed a consent form based on the study protocol approved by the review board of our university. The typical meal lasted from 60 minutes to two hours; during this time there were a number of interactions in the food and drink ordering routines. Therefore, across the four sushi bars, we recorded a number of instances of routine performances in which we could identify various patterns of interactions and then analyze a sufficient number of cases for each pattern.

\section{Methodology}

Ethnomethodological and conversation analytic research typically uses video data (Heath et al., 2010). We installed four to eight camcorders to record all chef/customer interactions from various angles. To record conversations clearly, we installed six to ten voice recorders at various locations. These audio and visual data were all synchronized for analysis. Thus, verbal utterances as well as body movements, gestures, gazes, and postures were analyzed. Although it is inevitable that people behave differently when being videotaped, we focused on routines that do not leave much room for participants to significantly change behaviors. Furthermore, our interest concerned how participants display their actions publicly (e.g., customers being watched by chefs and fellow customers), and observation is not necessarily anomalous to these settings. If one person acts or speaks in an irregular manner, this would be a noticeable event for other participants, and we can analyze how these other individuals exhibit their understandings of that action.

Following the standard conversation analysis procedure, we examined the sequential organization by which each action is explained in relation to prior actions (Heath et al., 2010; Schegloff, 2007). Participants themselves present the action in a recognizable manner situated in the particular context constituted by prior actions. When examining a routine, we as analysts do not simply characterize actions as a routine. Instead, we ask how participants themselves present and account for their actions as being done in accordance with a routine. For instance, chefs do not usually ask for drink orders when a customer has a full glass-in this case, the chef's question may be heard as a complaint that the customer should drink more quickly rather than as an order solicitation. By focusing on how 
participants themselves exhibit their own understandings of their actions, we do not need to construct our own interpretation. We can then confirm this analysis by showing that others in the situation understood this action as presenting an order taking routine, for instance, by starting to reply with a drink order. Similarly, we do not try to specify intentions people may have. We simply analyze how participants present a particular action to other participants and how these others react to it; participants themselves have no access to intentions other have but still achieve the organized interactions (Heath et al., 2010; LeBaron et al., 2016). The analysis focuses on the methods by which they achieve this organizing.

As we analyzed each of the interactions by following their respective sequences, we started to see several different interactional patterns. For instance, we observed that chefs placed themselves in front of customers and often engaged in action such as wiping a dish, putting ginger slices on a plate, or taking a glass away before initiating an order solicitation. Despite these variants of what was specifically done, we grouped these instances into one pattern in which actions seemingly unrelated to the order solicitation created the context for the subsequent action of order solicitation. The section below, which reports the empirical analysis, is organized according to these patterns; each subsection focuses on one pattern. Then, the analysis proceeded to identify cases that deviated from the identified patterns. In ethnomethodology, we carefully analyze how participants themselves orient to these cases as deviations from a norm and act accordingly; in this way the cases that deviate corroborate, rather than contradict, the analysis. The last subsection includes the analysis of these cases of deviations.

In tandem with this analysis, we sought a theoretical framework to explain the interactional patterns. The focus on recognizability emerged early in the analysis; it flowed naturally from the ethnomethodological orientation that pays attention to how participants present their own accounts of the actions. When the analysis revealed that the chefs switched between different routines, we saw the opportunity to relate our analysis to the ongoing debate in the literature on multiple routines and interrelations among these routines. The analysis also revealed that bodies and material objects were used in subtle ways to relate to other routines, which was connected to another debate on materiality. Once we engaged with these existing debates, we revisited the data and reanalyzed them and formulated our findings in terms of interrelatedness and materiality.

In the explication of analysis results below, we present transcripts of the interactions using the standard system of conversation analysis (see Appendix). To show gestures and body posture, we included some still images taken from the video, which are identified with Greek letters. These letters also appear below the line within the transcript to indicate the timing of the still image in relation to the talking. Additionally, we transcribed directions of gaze relevant to ongoing interactions; the lines showing gaze were added (the gaze is also shown by an arrow within the figure). Some gaze movements can take place prior to talking and the timing of these moves is indicated as spatial positions in these lines. Words (e.g., "Chf") indicate the items to which gaze is directed (namely, the chef), and arrows indicate the direction relative to the location one is facing-without any specific relevant person or object targeted. Commas ", indicate a shift of gaze, and minus signs "-" indicate that the gaze is fixed. For instance, "Chf---, $\downarrow---$ " means that the person looked at the chef (Chf) for a while, then started to look down and held his/her gaze there. The authors translated the original Japanese conversations into English. As much as was possible, we tried to make the translation as representative of the original Japanese and to keep the original word order so that the timings of talking and gesturing match.

\section{FINDINGS}

The overall pattern of the routines within sushi bars is shown in Figure 1-this figure, which is by no means exhaustive, is provided to give greater detail to the setting of the sushi bars in this study. The upper part of the figure represents activities of a customer or customers, and the bottom part represents service providers, namely the chef and other staff members. Some routines involve both parties while other routines are typically confined to either party. For instance, the ordering routine (order soliciting and placing) - the focus of this study-involves close interaction between the customer and the service provider. On the other hand, sushi preparation is a routine that officially involves only the chef and the staff of the restaurant. Eating and drinking are repetitive, routine activities for customers only. For the sake of simplicity, Figure 1 depicts the typical okonomi system in which customers order food and drinks in individual servings; in the omakase (predefined course) system, chefs first ask a customer what s/he cannot eat and then deliver food items without soliciting 
an order each time. However, drink orders happen throughout these predefined courses and customers often make additional okonomi orders after the course.

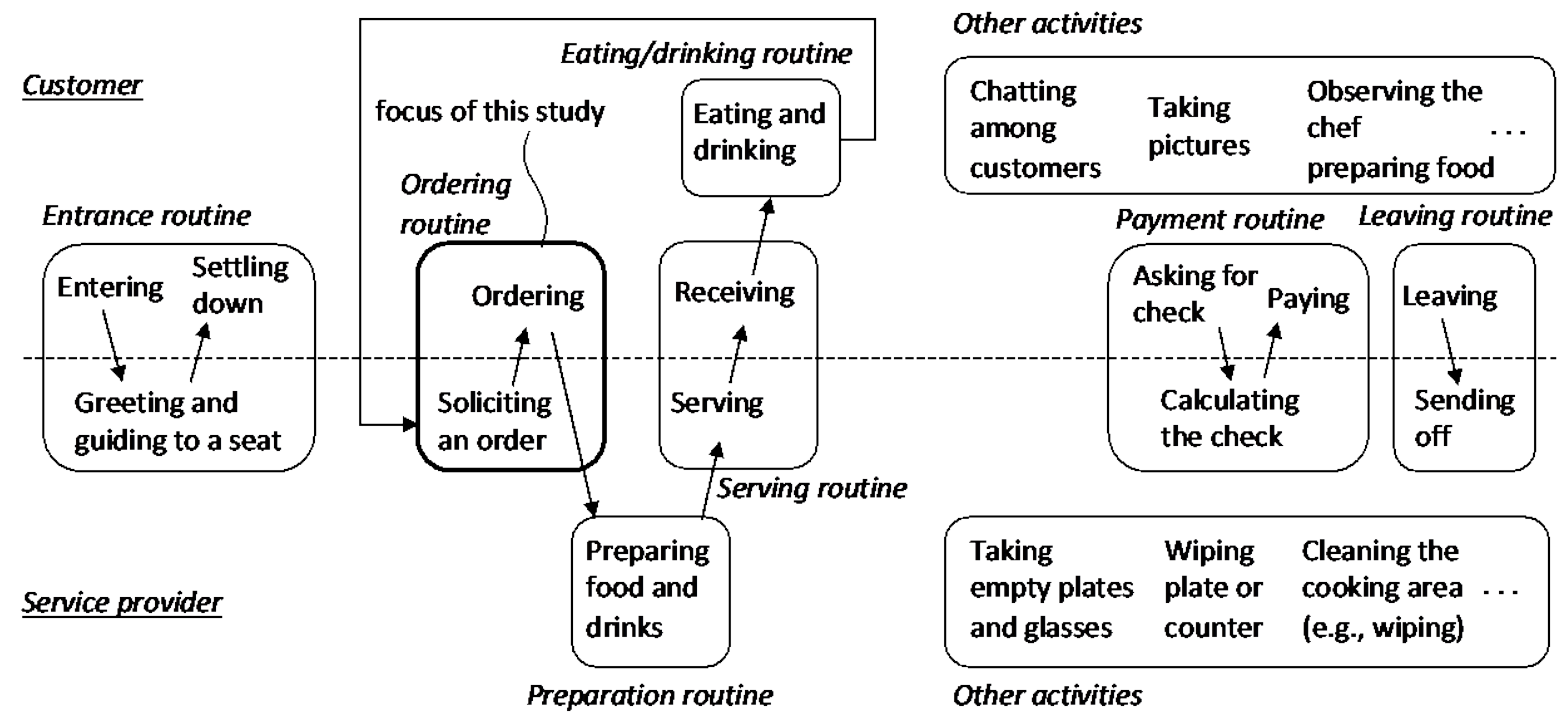

Figure 1: An overall pattern of routines at sushi bars

When customers arrive, they are greeted and guided to seats at the bar. The chefs then ask the customers for drink orders. Once the drink order is placed, the employees prepare the drink and serve it to the customer, who then drinks it. Thereafter, in case of the okonomi system, the chefs ask for food orders, typically beginning with some appetizers which are then followed by orders for sushi. In case of the omakase system, the chefs begin by asking about particular food items that the customers might not like or be able to eat and thereafter start serving dishes according to the predesigned course. Eventually, the customers need to indicate that they want to conclude the meal and ask for the bill. The customers then pay and leave.

Typically chefs speak to customers to solicit orders. A prototypical sequence unfolds as follows: A chef asks an order-solicitation question; the customer answers with an order item; the chef acknowledges the order; the ordered item is delivered to the customer. This sequence is then repeated for subsequent food and drink orders. Yet, in reality this prototypical sequence is quite varied. Although chefs ask questions, such as "Would you like another drink?", the analysis examines how this question is made possible through a sequence of preparatory actions. In the following subsections, we begin with how the initial action is made possible through prior actions and then move to how alignment is achieved following the initial action.

\section{The Beginning of Routines}

A commonsense way to initiate an ordering routine is perhaps for a chef to explicitly and verbally address the customer. We seek to show that even this most explicit address does not automatically start a routine performance and cannot be done without prior coordinated actions that make a particular address recognizable. After looking at this type of initiating, we examine cases where the chefs use subtler methods of initiating a routine without such explicit addresses.

\section{Beginning by Explicit Address}

In Fragment 1, the chef indicates that he is talking to a particular customer by addressing the customer by name and gesturing by hand (line 01). In this case, the customer was a regular patron at this sushi bar and hence the chef knew his name ("Goto," a pseudonym). The analysis reveals the important work done that allows the ordering routine to successfully begin and unfold. The chef had served a dish to a different customer, a different routine (the still image at $\alpha$ is shown below), and returned to the position where he had been cooking (yet another routine) in front of this customer, A4. As he was returning to this position, he could observe the customer and most likely noticed the empty glass. Smoothly after returning to the regular cooking position, he settled in a formation of facing the customer $(\beta)$, allowing the explicit address of the customer's name. Therefore, the explicit address does not start abruptly but in a readily recognizable manner. Materiality, such as the bodies and the 
physical space, was consequential to this initiation. In transcripts reported here, Chf indicates a sushi chef. Customers are referred to based on combinations of letters and numbers; the letters A, B, C, D refer to the four sushi bars we studied and the numbers are assigned uniquely to customers.

\section{Fragment 1}

((Chf serves the customer sitting left side of A4. $\alpha)$ )

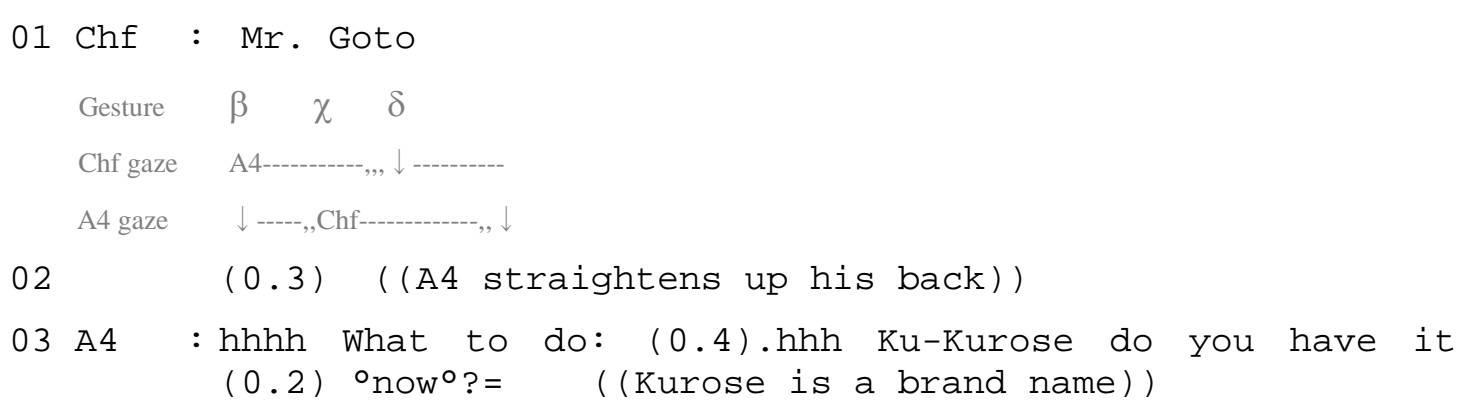

$04 \mathrm{Chf}:=$ Kurose: we do have it:

((They continue discussing which brand to pick.))

$\alpha$

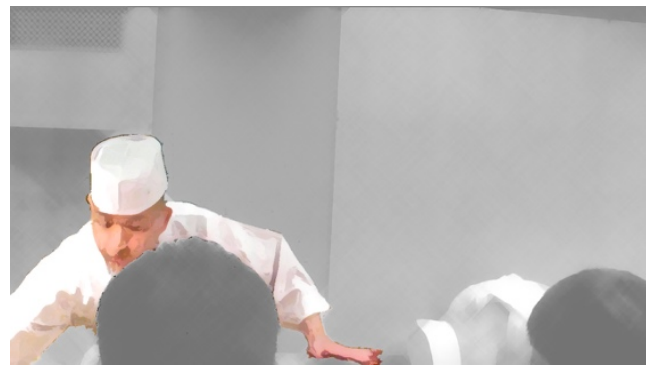

$\chi$

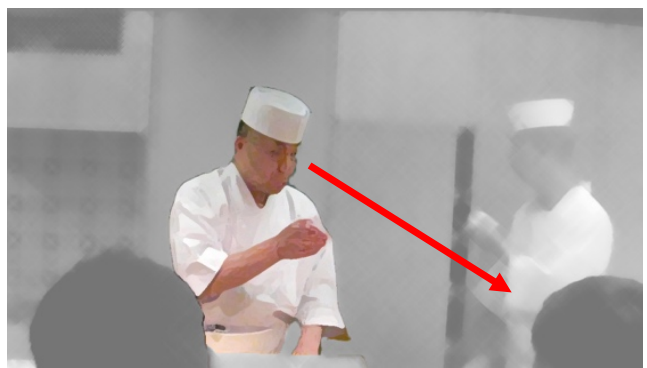

$\beta$

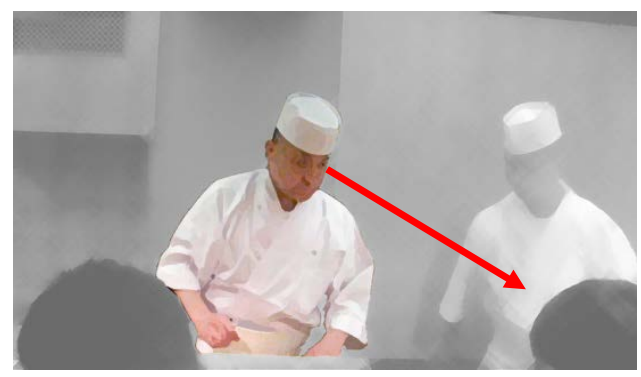

$\delta$

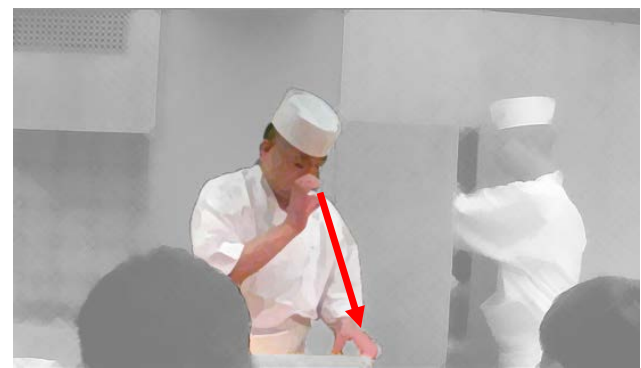

In addition to addressing the customer by name, the chef extended his right arm toward $A 4(\chi)$. While the chef was making this move, the customer looked back at the chef. The chef then looked down and produced a pantomime of drinking $(\delta)$. The customer then looked down, but by straightening his back showed that a response was forthcoming. We see from the customer's response with an order item in line 03 that he immediately understood the pantomime of drinking as an act of order solicitation, and for instance, not the beginning of a discussion about whether he liked the drink he was drinking. The chef's body position, posture, and gaze were coordinated to create the assemblage in which the routine could begin. The figures show that the chef would naturally face this customer as he returned to his position from delivering food to a next customer. There was no need to do much to create the formation. Note that the chef did not return to this position to talk to this customer; this was almost at the same location he conducted a food preparation routine. In this sense, we can see that three routine performances were interrelated, food delivery, food preparation, and order solicitation. Further, this interrelation is coordinated with various elements of materiality. The cutting board that was placed directly in front of the chef allowed him to use his gaze toward it as a reference to another routine, that of food preparation. The body posture, gaze, and the cutting board all formed the assemblage that made the question and the pantomime possible.

Yet, note also that even after this initial sequence of question and the pantomime, the routine was not completely demarcated from other routines in the situation. After obtaining the customer's gaze, the chef immediately looked down to the cutting board, projecting a return to the routine of food preparation. We will revisit these types of actions in more detail later, and here only suggest that this 
ambiguous action by the chef of returning to his work allowed the customer, who then straightened his back to respond, some time to answer the question. In other words, the chef was not demonstrably waiting for an answer but had his own work to do until the customer was ready to reply.

In summary, this example shows that the chef explicitly addressed the customer in initiating a routine performance, and that this was made possible by the sequence of various subtle actions leading to that point. Furthermore this initiating of the routine performance was conducted in interaction with other routines at the moment and various material objects.

\section{Beginnings in Relation to Another Routine}

One subtle way to initiate a routine, without an explicit address, is to move close to the customer while still engaging in some other work. The following fragment occurred as the chef approached a customer to put pickled ginger slices on the customer's plate. Thus, the chef could easily initiate the routine performance because he was close enough to this customer. The interaction below is a variant of the ordering routine, asking not what the customer likes, but what the customer does not like.

\section{Fragment 2}

((Chf puts pickled ginger on $\mathrm{A5}^{\prime} \mathrm{s}$ plate.))

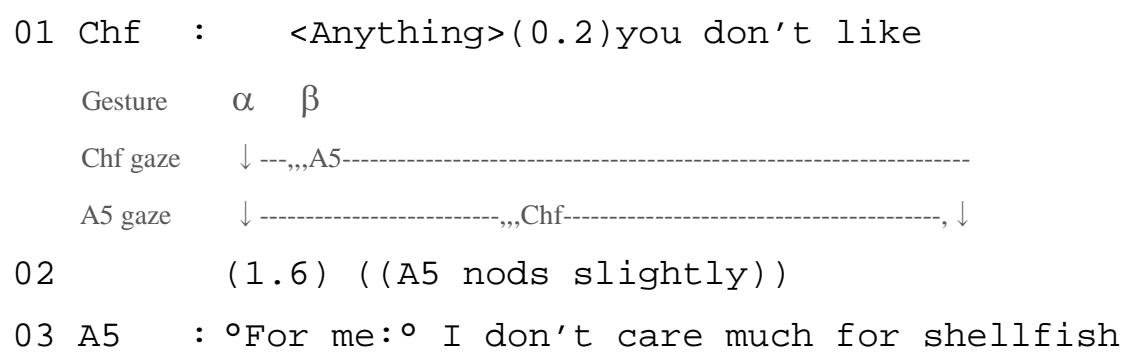

$\alpha$

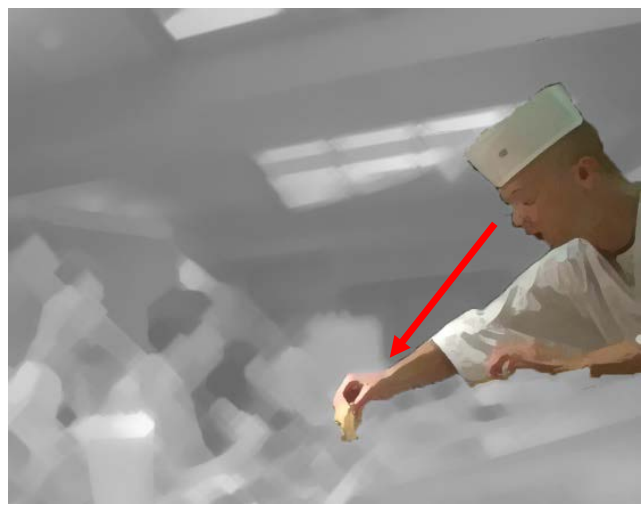

$\beta$

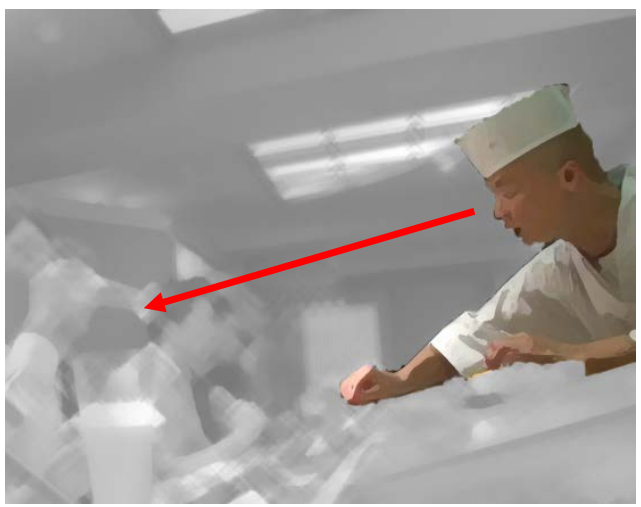

When the chef was about to finish placing the ginger slices on the plate $(\alpha)$, he directed his gaze to the customer in front of him and uttered the first line $(\beta)$. In this manner, the chef could speak to the customer naturally because he was already in close proximity to this customer. The chef also started with a slow utterance of "Anything" and paused slightly, to obtain the customer's gaze (See, Goodwin, 1980). When the customer looked up at him, the chef then continued, "you don't like." Therefore, in addition to putting the ginger on the plate, the chef staged his utterance to make sure the customer was orienting to him. This rather short and cursory question in line 01 was made recognizable by the subtle actions.

Briefly, in another routine of food delivery, the materiality of pickled ginger and the chef's body all constituted the assemblage that made the sudden talk possible. As a result, the customer immediately provided his answer without any indication of change-of-state (Heritage, 1984) of his prior situation; that is to say, his answer was naturally forthcoming without an explicit effort to halt a prior activity and move into this interaction. Putting ginger on the plate is a natural part of the service for which neither the chef's explanation nor the customer's response is needed-this can be seen from the fact that the customer did not present the need to respond. In contrast, the customer immediately presented his act of responding to the chef's question in line 01, e.g., with his gaze and nodding. Therefore, we see that these two activities, namely putting ginger and asking about undesired food items, were treated as being unrelated. 
In the following fragment, the chef greets customers and then asks for drink orders. This example shows that the chef initially moved closer to the customers to grab a piece of fish from the case in front of the customer, and subsequently, in the middle of that action, he spoke to the customers directly to issue a greeting. The order solicitation is then done naturally as an extension to this greeting.

\section{Fragment 3}

( (A1a and A1b are chatting. Chf approaches A1a and A1b.))

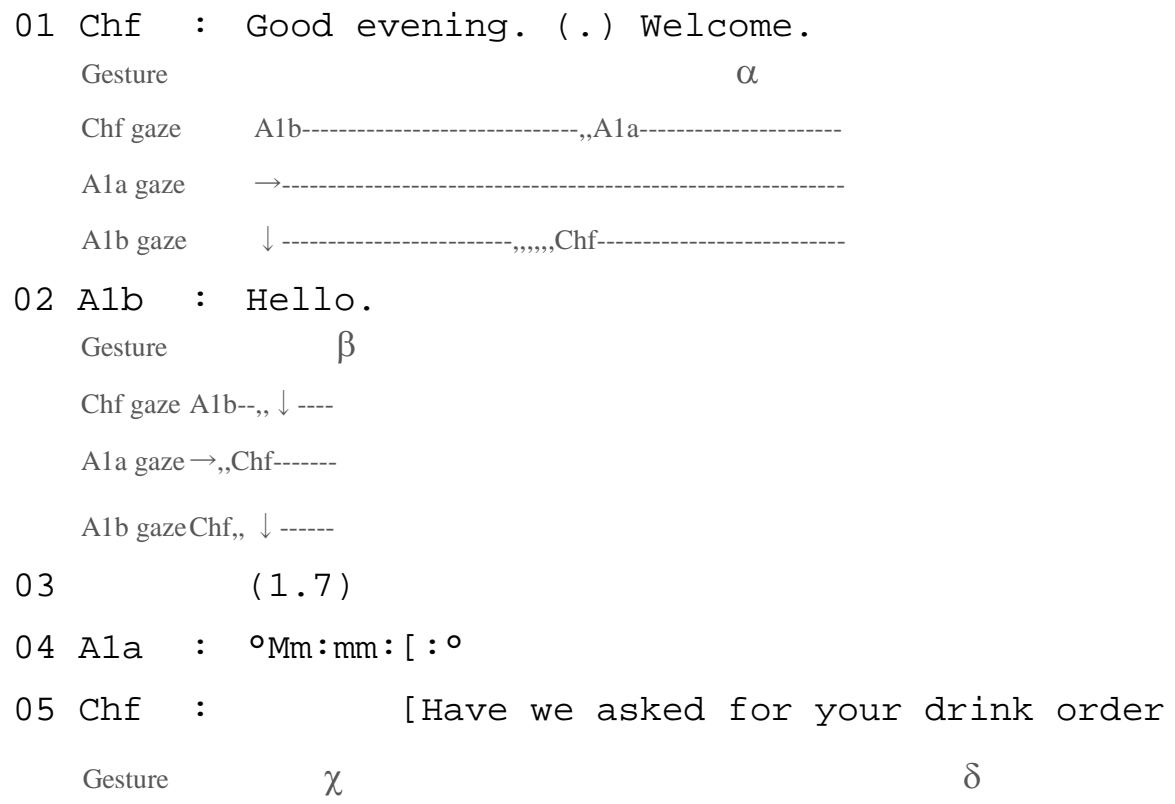

06 A1a: Ah (0.3) no.

$\alpha$

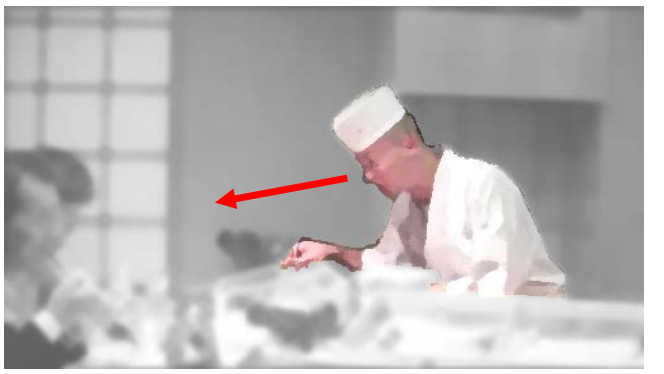

$\chi$

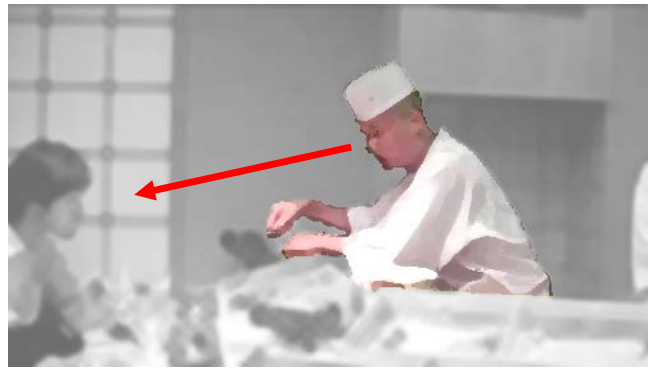

$\beta$

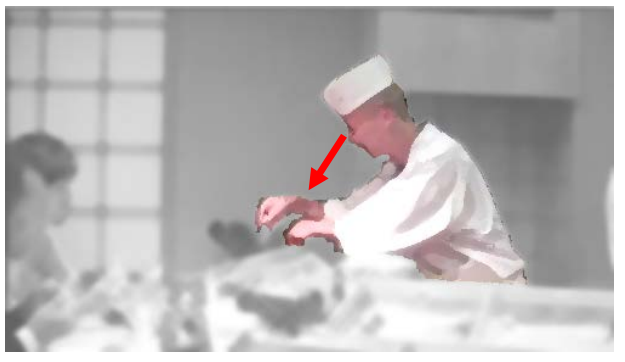

$\delta$

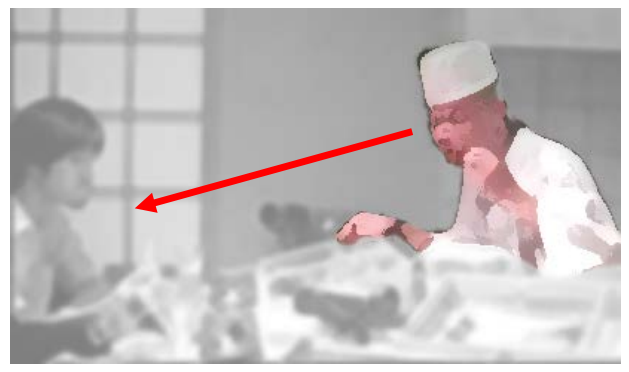

The chef approached the customers and greeted them in line 01 . When he was about to finish saying, "Good evening," A1b turned his gaze at to the chef. Once A1b's gaze was directed at him, the chef then looked at A1a - these two customers were in the same group - and said, "Welcome" while bowing $(\alpha)$. At this moment, the chef had his hand on the handle of the glass case. As the chef finished this greeting and A1b responded with "Hello" in line 02, the chef looked down and opened this glass case where blocks of fish are displayed $(\beta)$. The chef glanced at the customer $(\chi)$ and said, "Have we asked for your drink order," eventually looking at the customer's face $(\delta)$. In this fragment, we can see that the assemblage was already set up as a continuation of the greeting sequence (line 01-02) and the act of picking up the block of fish when the order solicitation sequence started in line 05 . The routines of greeting, order solicitation, and food preparation (taking fish from the case) were all closely coordinated. Furthermore, the fact that the chef paused during the act of picking up fish when starting 
to solicit for an order indicates that these two acts were presented as unrelated: The customer reacts not to the chef's act of picking up the fish but only to his greeting and order solicitation.

In summary, the routine of order solicitation did not happen abruptly when a chef asked a customer a question. Prior work, which is closely coordinated as part of other routines, was needed. In addition, various material objects and bodies shaped the situation to create the assemblage that allowed the routine performance to be readily recognizable and initiated. Note that the ginger slices and the fish in the case were not obviously a part of the ordering routine but were performatively consequential for its initiation. The chef's body was also not necessarily fully devoted to the focal routine performance but allocated to various other routine performances at the moment. These ambivalent uses of materiality were consequential for the routine performance to unfold in a recognizable manner.

\section{Alignment of Actions}

Even if an action is successfully taken to initiate the beginning of a routine, the routine performance cannot automatically unfold; participants' actions need to align with those of the other individuals involved. The point of this analysis is to show that further work is needed to achieve the beginning of a routine, which is done by using and referring to other actions and materials that are not seemingly part of the routine. In this way, a sequence of actions can successfully make itself recognizable as the performance of a particular routine.

The analysis will reveal several methods by which actions are aligned in relation to some other previously ongoing routine performances. In the first method, after the chefs have initiated a focal routine performance, they begin a different routine performance. This allows customers time to think. In the second method, the chefs continue to engage in a different routine performance while initiating a focal routine. Once these methods are established, we also report some cases that deviate from these patterns, where chefs pause the performance of an ongoing routine and pay full attention to the focal routine. However, we will show that the chefs ask rather quick questions, which customers were expected to answer promptly; that is, these questions were easy enough that the customers did not need to consider how to respond. Hence, we argue that the chefs themselves orient to these methods. We will review each method in detail.

\section{Alignment by Switching to Another Routine}

Here, we examine a case where the chef switches to a different routine after initiating an order taking routine. The chef directs his gaze at the customer but quickly looks back down at the cutting board after securing the customer's gaze, projecting his switching to another routine of food preparationthe same pattern as Fragment 1. After a few moments, the customer finally indicates an item to order.

\section{Fragment 4}

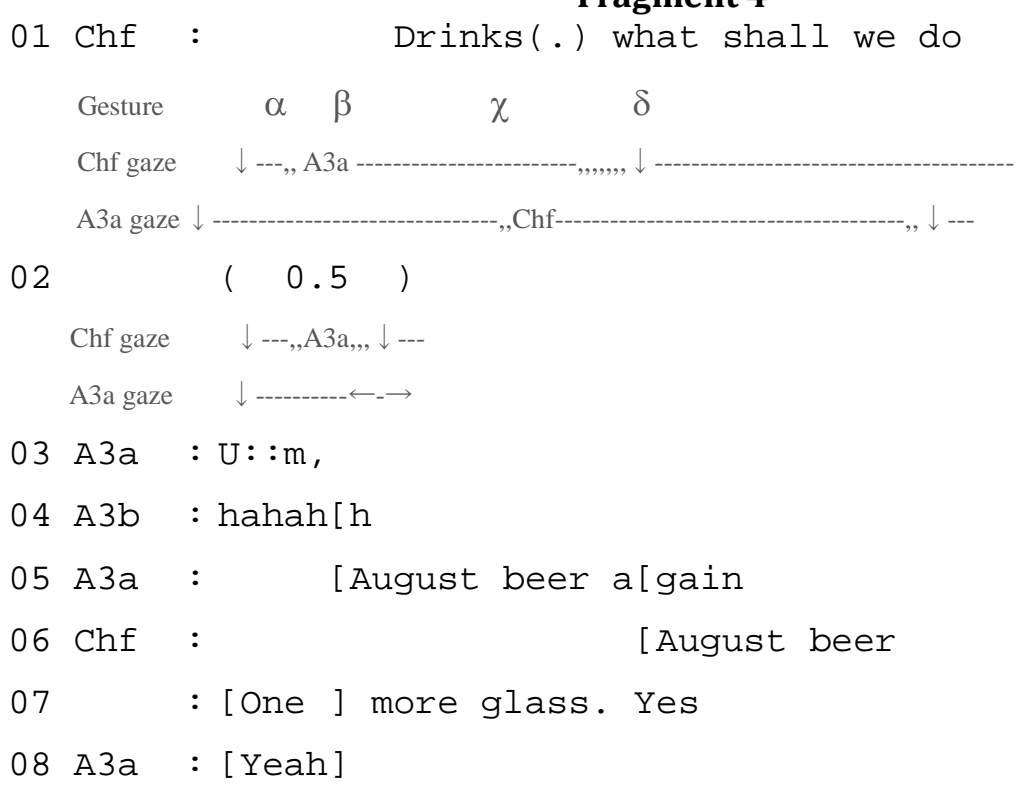


$\alpha$

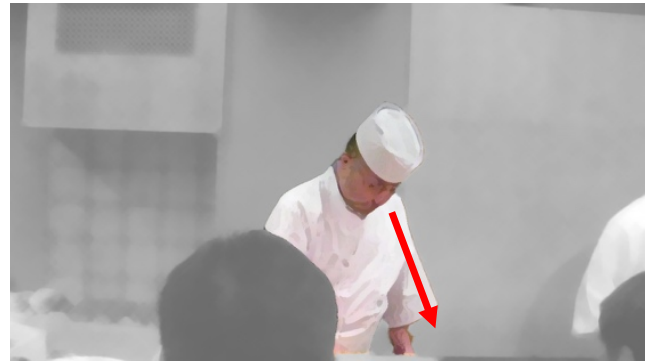

$\chi$

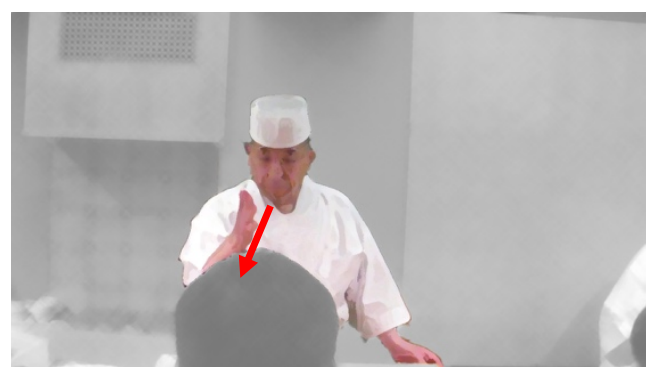

$\beta$

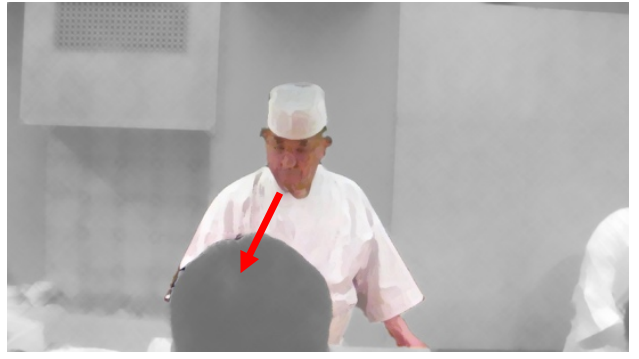

$\delta$

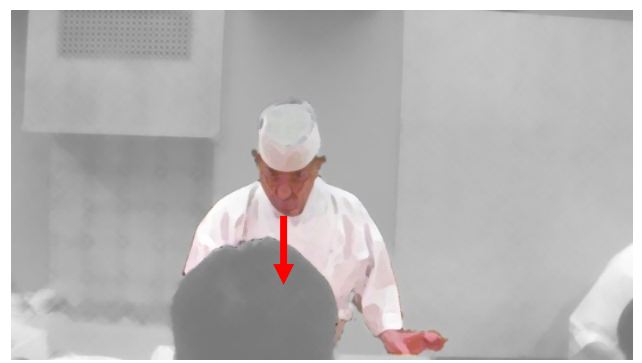

Here, the chef was looking down while preparing food $(\alpha)$. Then, the chef looked at the customer who was finishing his beer $(\beta)$. Thereafter, the chef raised his right arm while looking at the customer and then said, "Drinks" $(\chi)$. A3a then looked back at the chef and the chef looked down (at the food that he had been preparing) and said, "What shall we do?" $(\delta)$. That is to say, the chef initiated the interaction by raising his arm and looking directly at the customer, but then he immediately switched back to another routine of preparing food. The customer then took a moment $(0.5 \mathrm{sec})$, looking around, to show that he was thinking; during this time, the chef glanced at the customer once. As the customer specified a drink item (line 05), the chef then looked back at the customer and acknowledged the order (06-07). This way, the chef not only gave the customer time to think but also continuously divided his attention - with the brief glance while waiting for the customer's response-between the focal routine of order taking and the routine of preparing food.

In short, after successfully initiating the order taking routine, the chef returned to another routine performance, preparing sushi, allowing the customer time to think. If the chef had stood still, looking at the customer, the customer would likely have felt pressured to respond immediately. On the other hand, if the chef had left the customer alone and completely focused on action of preparing sushi, the customer would not have been able to easily respond. Therefore, the chef remained subordinately in the focal routine and glanced at the customer while working on the food, showing that he was orienting to the customer's expected response. Thus, we can say that the chef remained on the edge of the routine-both inside and outside it at the same time-so that he and the customer could align their actions to perform the routine. These actions were largely conducted with the material body posture, gestures, and gaze in relation to the material setting including the cutting board. The chef kept his upper body facing the customer, maintaining his involvement in the ordering routine while moving his head and gaze to the food preparation routine. In sum, the alignment required engagement with other routine performances and ambivalent uses of materiality that is not exclusively part of the focal routine.

We observed various other ways to construct the context but cannot report all for lack of space. For instance, chefs often started to wipe the counter, the cutting board, or their knives, and then wring a dishcloth after issuing an initial question. Compared to preparing sushi by hand, the act of wiping appears more lightweight, thus the chefs can return to the ordering routine quickly. In the case of preparing sushi by hand, chefs maintained a body posture facing the customer to show their ongoing attentiveness.

\section{Alignment by Continuing Ongoing Work}

Next, we will report a case where a chef continues with an ongoing routine performance of preparing sushi while starting a new order taking routine. Unlike the previous case where the chef stopped his ongoing activity, the chef in this case continues the routine performance without even looking at the customer. In this way, the chef shows that he is busy with his work and does not impose much pressure on the customer to respond quickly; the customer then takes ample time to answer. This is a regular 
customer who knew this sushi bar well.

\section{Fragment 6}

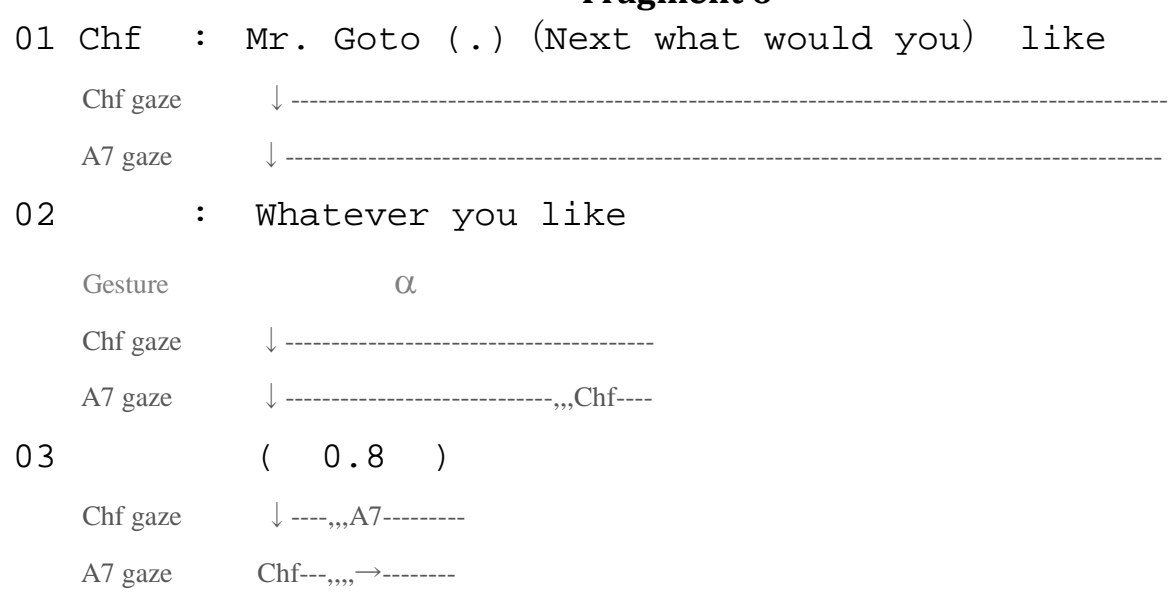

04 A7: Mm:

05

(1.0) ((A7 looking at the glass case to the right))

๑6 A7 : I'll get sea eel for sure.
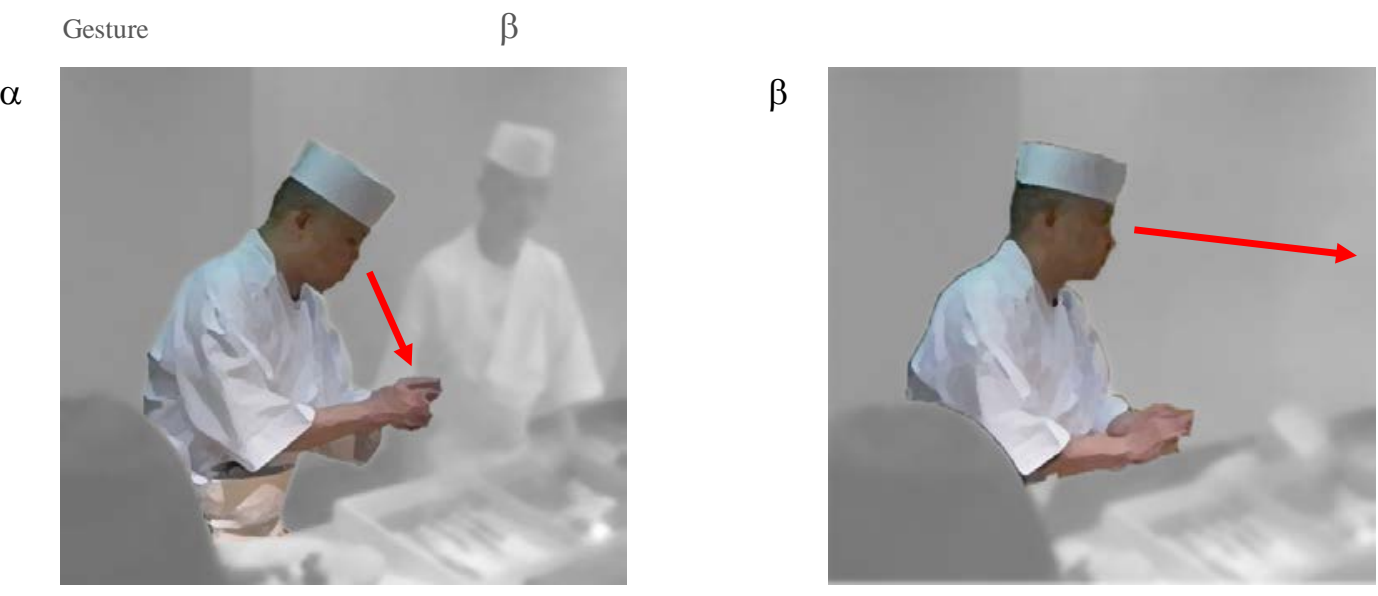

In this case, the chef continued preparing sushi by hand, without stopping his hand movements while talking to the customer. Nonetheless, it is important to note that the chef happened to have his body facing this particular customer while preparing the food; specifically, he could start talking without moving his torso. Although he continued looking down (line 01-02), he occasionally glanced at the customer (line 03); by that time, the customer had turned his gaze to the chef (line 02). Then, when the customer started to answer with the item he wanted, the chef tilted his head up and looked at the customer $(\beta)$.

The reason the chef did not stop his sushi preparation routine seems to be related to the fact that he knew this customer well; usually it would be rude not to look at the customer when speaking to him or her. Saying the customer's name appears to show this utterance carries a personal relationship rather than being rude. While these discussions are interesting, for our purpose it is enough to note that the routine of ordering was done in a way that allowed the chef to detach himself from it but at the same time maintain his peripheral orientation to it. While the act of preparing sushi continued, neither the chef nor the customer made it a relevant topic to discuss; the customer's attention was fully devoted to the act of ordering sushi. These two activities were treated as unrelated.

These two methods suggest that the beginning of a routine performance was achieved by incorporating other routine performances within the focal routine performance itself. To do this, various material objects were enrolled such as ginger slices, the fish case, the knife, and the dishcloth, as well as the chef's body. These objects and bodies appeared unrelated to the focal routine but were in fact performatively consequential parts of the focal routine. The chef's body was particularly flexible in maintaining multiple involvements, e.g., he kept his head down, looking at the sushi he was 
preparing, while his torso faced the customer. Through this elaborate sequence of actions, the performance can make itself recognizable as a particular routine and thereby initiate itself.

\section{Deviations: Maintaining Gaze at a Customer}

Next, we review what appear to be deviations from the above methods. There were a few cases in which the chefs continuously directed their gaze at a customer rather than initiating or continuing another routine performance. In fact, this method was seen in Fragments 2 and 3 above. The analysis shows that in these cases, the chefs' questions were rather lightweight, thus answering them could be straightforward. In Fragment 2, the chef was asking the customer whether there was anything he did not like or could not eat. In this case, an answer should follow immediately because one would know what one does not like or cannot eat. Therefore a customer would not require time to think about a response. The same analysis can be made of Fragment 3, where the chef continuously looked at the customer while asking a Yes or No question ("Have we asked for your drink order"). The customer could immediately answer, "No." If the chef had started to engage in another routine after issuing these lightweight questions, this action might well have been somewhat confusing as the customer might not know whether she should answer immediately.

In the following case, there is a more salient deviation. Here, the chef slightly pauses in the ongoing routine of preparing sushi, and then he continuously gazes at the customer. In this manner, the pressure on the customer to quickly respond appears to be high because the chef was signaling a return to preparing sushi following the conversation-a quick answer was expected from the customer.

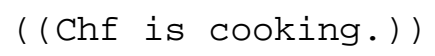

\section{Fragment 7}

( (Chf looks down but soon looks back at the customer and continues the conversation.))

$\alpha$

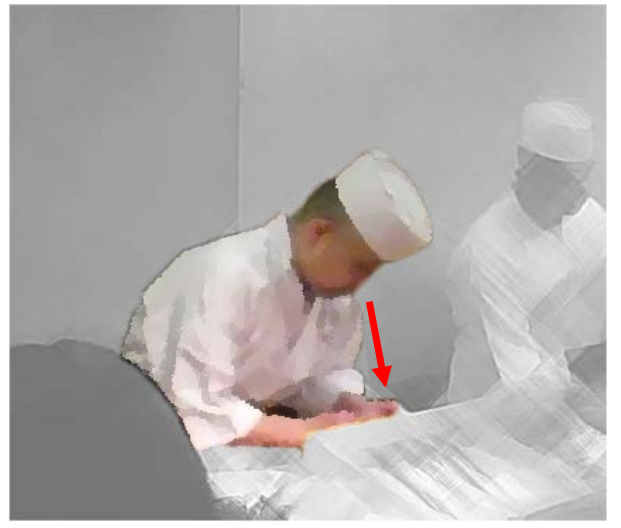

$\beta$

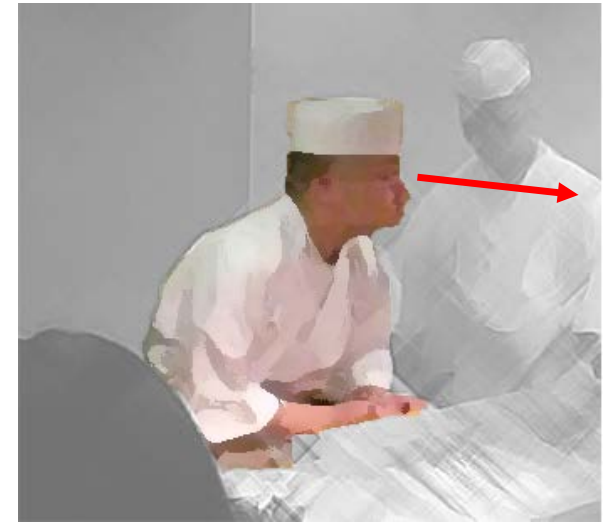

The chef was looking down while preparing food in front of the customer $(\alpha)$. He then looked up at the customer. After that, the customer looked back at the chef. At this moment, the chef said, "Alcohol okay." Here, his hands were still on the food he had been preparing, yet he stopped moving his hands and thus ceased this activity as he spoke $(\beta)$. Therefore, he paused the food preparation between his question and the customer's answer. To be precise, he used two different parts of his body to allocate 
his involvements into two activities, namely hands for sushi preparation and head for order solicitation (c.f., Schegloff, 1998).

The form of the question appears to be related to this. "Alcohol okay?" is different from the other questions, e.g., "what would you like?", and "drinks, what shall we do?", in that it is a Yes or No question. The customer could answer simply, "Yes". Furthermore, this is likely related to the fact that the customer's glass was not empty, and therefore the question might appear not so much an immediate order solicitation as making sure the customer is okay, e.g., checking how the customer is enjoying his drink. In this case, the customer presented his understanding that this question was an order solicitation and responded accordingly, indicating that he needed to finish the rest of the beer before making another order.

We can see something similar in the following fragment. Again, the chef holds his gaze once he issues a question as to whether the customer wants to skip some of the items on the course because she is already full. The customer and her companion take time to respond but the chef maintains his gaze at the customer. Again, the pressure seems to be particularly high.

\section{Fragment 8}

( (D1b asks D1a whether she is full (left figure $\alpha$ ) and D1a answers affirmatively but laughs. Chef responds by saying, "You are full? Getting full, aren't you? I see that." $(\beta))$ )

$\alpha$

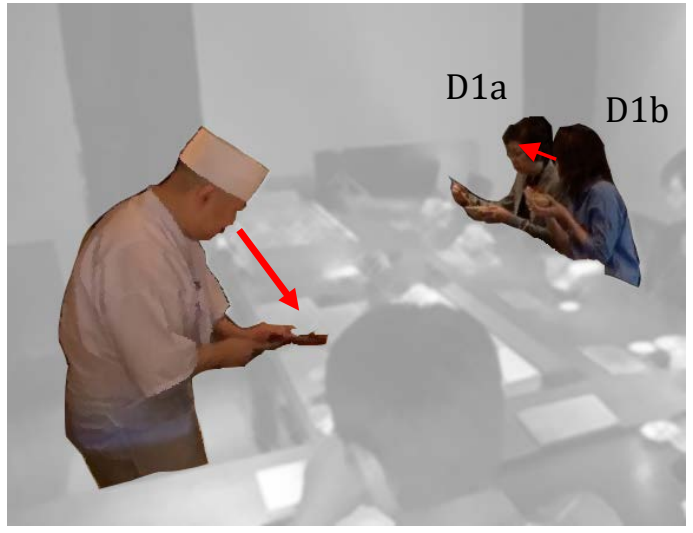

$(8 . \odot)$

01 $\beta$

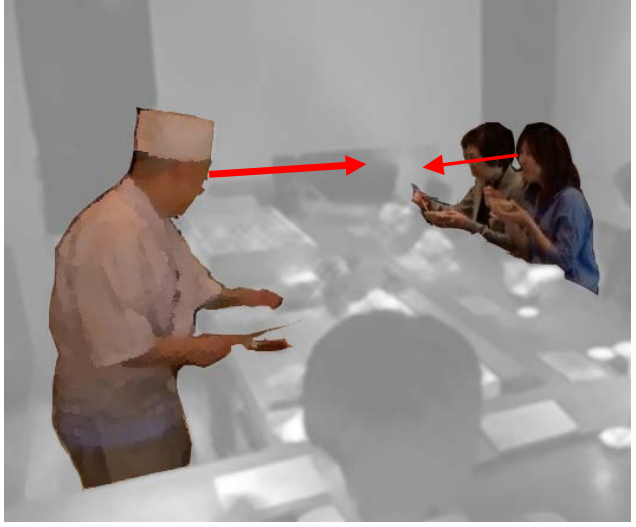

02 Chf : We will have octopus (.) sea eel egg and

Gesture

$\chi$

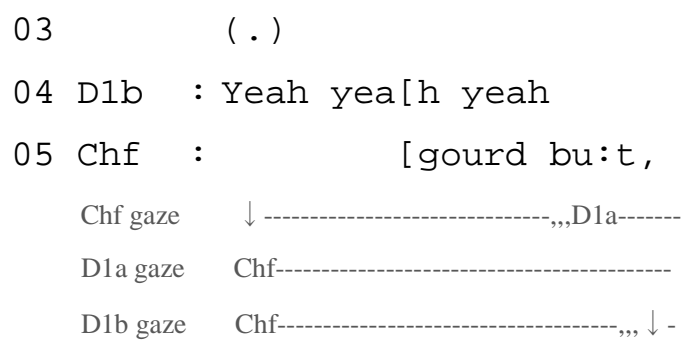

06 D1b : Uh:[m

07 Chf : [.hh what would you do

Gesture

$\delta$

Chf gaze

D1a-

D1a gaze

D1b gaze

$\odot 8$

: Will you skip octopus?

Chf gaze

D1a, $\downarrow-$

$-, \mathrm{D} 1 \mathrm{a}$

D1a gaze $\downarrow$

,Chf- 

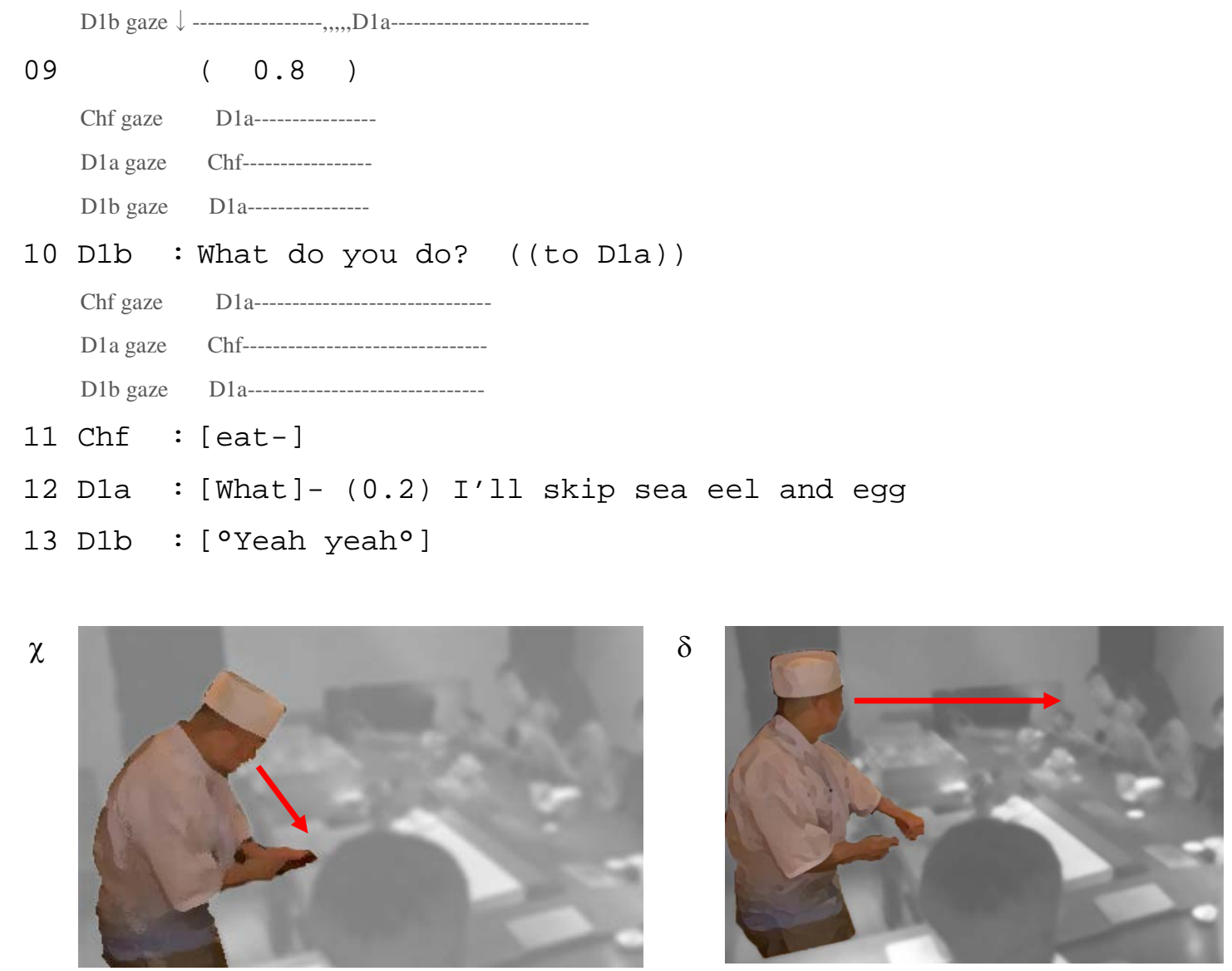

Note that when D1b asked D1a whether she was full, Figure $\alpha$ shows that D1b was looking at D1a and the chef was looking down, indicating that this conversation was between the customers, while it was loud enough for others can hear. The chef then overheard this conversion and acknowledged it, and at this moment, D1b turned to the chef $(\beta)$. Therefore, we can see that this conversation was officially unrelated to order placing because the chef was not officially part of the conversation, rather his participation was subordinate (Goffman, 1981). Then, the chef continued preparing food, directing his gaze downward at this task. While he was looking down and slicing the octopus $(\chi)$, he started to speak in line 02 , after 8.0 seconds of his prior acknowledgement. Then, eventually he looked at the customers in lines 05 to $07(\delta)$. He maintained his gaze at D1a, except for a glance back down when he moved to put the remaining octopus back in the case. Therefore, the chef mostly paused his work, asked a question, and continued to direct his gaze at the customer.

Again, this fragment differs from the patterns described above. The explanation for this is similar to that of the previous conversation fragment showing deviation: the chef's question, "Will you skip octopus?", was a Yes or No question. In this case, however, the customers started to briefly caucus among themselves, and the answer was not immediate. The chef could obviously hear this discussion between the customers, and he kept his gaze directed toward these customers. Note in this case that it was the customers who suggested that they might not want to eat more in a loud enough voice that the chef would be able to hear. In other words, it was the customer, not the chef, who suggested that she might possibly skip some of the sushi selections. Therefore, answering the chef's question should not be that problematic for them. This explains why, after eight seconds of silence, the chef rather abruptly and without preface started listing items to skip, without even looking at the customers (line 02). In short, these cases do not contradict the methods discussed above, but rather support our analysis; the participants are orienting to how much time customers are allowed to respond.

\section{DISCUSSION}

\section{Summary of the Routine Initiation Process}

The findings are summarized in Figure 2. When we outlined the overall pattern of routines of sushi 
bars in Figure 1, many activities were shown to be disconnected from the focal ordering routine. However, here we can see that the ordering routine performance is tied to these seemingly unrelated activities.

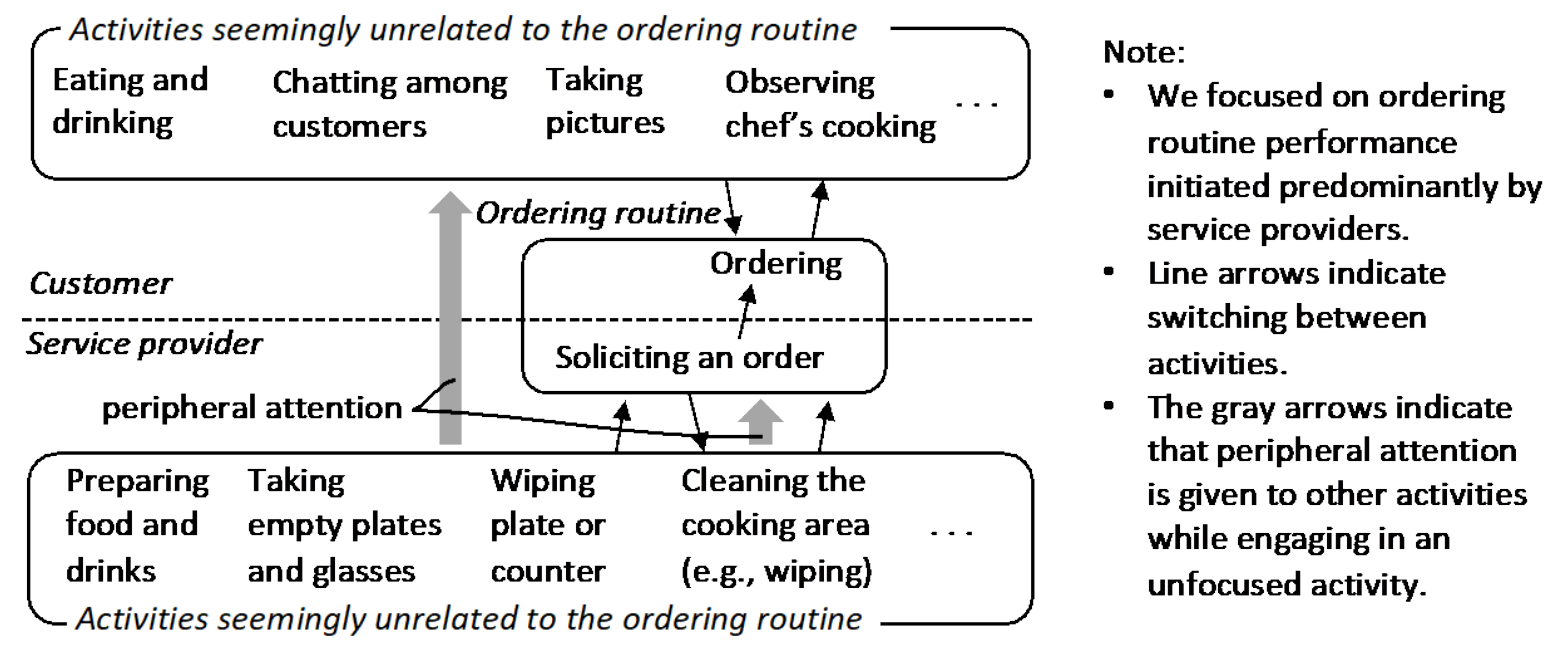

Figure 2: Summary of ordering routine performance

The first important point in the analysis is that the initiating order solicitation actions were not abruptly produced. Routine recognizability requires preparatory work even before the initiating actions; the chefs could easily start speaking to the customers because of the prior coordinated actions that were shown to be unrelated to the focal routine but were related to other routines. This also means that chefs were paying peripheral attention to a customer's situation while simultaneously engaging in their own activities such as food preparation. Namely, the chefs observed the customer's availability for a possible interaction, e.g., noting empty glasses and plates. These prior actions then constructed a certain assemblage with the arrangement of bodies and objects that made it possible to produce the initiating actions. These other actions either continued or were terminated.

The second insight was that once the initiating action sequence started, chefs often switched to another routine performance. For instance, a chef might switch to food preparation or cleaning the counter. This switching was done in a smooth manner by a chef, who was typically looking down at the cutting board and continuing the hand movements of food preparation. The switching afforded customers some time to ready themselves to align their action to the focal routine. Minus this switch, the chefs would have continuously looked at the customers and thereby exerted pressure on the customers to respond immediately. On the other hand, when it was mutually expected that the customer could immediately respond, e.g., lightweight questions, this switching did not happen. Therefore, whether this switching happens depends on the way previous actions frame the context. The third insight was that while the chefs had switched to another routine, they did not disengage from the focal routine but maintained the peripheral attention to the customers by, for instance, occasionally glancing at the customers. Although they would look down at the food they were preparing or at the cutting board they were wiping, they maintained a position in which their bodies faced the customers. This allowed a chef to be open at any time to the customer's response. Once the customer responded and aligned his or her action to the focal routine, then the subsequent sequence unfolded. While engaging in unrelated actions, chefs remain on the edge of the routine by being indirectly attentive to the customers.

\section{Recognizability through Interdependence}

The concept of routine, as long as it is understood as performative, involves not only the focal routine but also other seemingly unrelated routines. Therefore, actions become recognizable as the performance of a routine with some kind of boundary only through actions that traverse the boundary, orienting to what is both inside and outside the routine boundary. In contrast, if everything is explicitly relevant, e.g., an employee squarely approaching a customer and holding her gaze on him, it would be difficult to achieve the routine as such; more explanation may well be needed. By moving subtly into and out of a routine, participants can start performing a routine.

This study supports the view of prior research that a routine performance triggers another routine in 
order to orient to specific ostensive patterns (Spee et al., 2016). Specifically, sushi chefs switched back to other routines after initiating a focal routine so that the standardized order taking routine can be achieved. The current study makes an additional contribution by showing that such ostensive patterns are achieved as a result of the interaction with other routines, not simply that multiple routines exist recognizably first and then interact with each other. When the alignment of multiple participants is needed for the routine to unfold, participants need to move out of the focal routine and engage with another routine in order to achieve an ostensive pattern and recognizability among the participants. How this is done depends on the participants' professional skills (Spee et al., 2016). Professional skills are used not only to make discretionary judgments as to whether and how to initiate other routines to achieve a certain ostensive pattern but also to make a performance recognizable and achieve the ostensive pattern in the first place through relating to these other routines. Professional skills are also needed for judgment on whether to leave out other routine performances that may not be needed for a particular routine.

The routine performance often deceives us into viewing the routine as closed with a clear boundary; once the routine performance achieves its recognizability as a routine, it retrospectively appears to exist on its own-it becomes black-boxed. In fact, the findings suggest that the routine performance itself seeks to hide the interrelations, so to speak. For instance, when sushi chefs switched to other routines, they presented these other routines as unrelated to the focal routine. If these other routines had clearly been part of the focal routine, then the customer would have had to pay explicit attention to them and immediately react. In other words, unrelatedness was a critical part of the interrelation. Although black-boxed, interrelatedness is nonetheless always present implicitly. According to Kremser and Schreyögg (2016), routine interdependence is not simply a matter of connected tasks in workflow; the routines are interrelated "through a network of mutual anticipations" such that "each routine presupposed certain aspects of other routines," resulting in a tightly integrated cluster of routines (p. 706). This study has revealed that the subtle, hidden interdependence, which needs to be achieved within each performance, constitutes such a network of mutual anticipations. This nuanced understanding of routine interdependence is important if we seek to understand how a routine fits and alters the ecology of routines. We need to pay attention to subtle and often hidden interdependence as well as explicit cases of interdependence.

In sum, this study extends the findings of prior research by bringing to the fore the recognizability of routines. Through subtle and often hidden interrelations with other routines, the performance of a focal routine can achieve its own recognizability. This is because actions are made recognizable, or accountable in ethnomethodological terminology, within a specific context constructed through various subtle actions. Without such efforts, these actions would happen abruptly and require explicit explanations. By examining how social order is achieved through mundane actions, ethnomethodology has been proven useful in revealing the creation of recognizability. Particularly, the subtle coordination between multiple activities has been studied under the theme of "multi-activity" (Haddington, Keisanen, Mondada, Nevile, 2014). If we simply assume that routines exist first and then interact with each other, we miss how the performances become recognized as routines in the first place.

\section{Recognizability through Materiality}

Materiality has been central in the discussion of routine dynamics (D'Adderio, 2008; 2011; 2014; Pentland et al., 2012; Pentland and Feldman, 2008). Emphasizing recognizability, we no longer consider that a routine exists first and that subsequently it uses materiality. Material artifacts do not interact with routines from outside; they are at the center of a routine (D'Adderio, 2011). In terms of recognizability, routine performance reflexively assembles particular material objects and then uses them to make itself recognizable as the performance of a particular routine. Therefore, the routine performance is not simply embedded in a given context; the performance is "enacted through the context" (D'Adderio, 2014, p. 1347) such that it assembles a context that makes itself possible in varying manners. The analysis presented in this study confirms these points.

In addition, the above analysis has shown that material objects obtain rather complex meanings through routine performance. While these objects were consequential for the ordering routine, they did not directly reference the particular routine. For example, the ginger slices-a food item-did not allude to the ordering routine; the chef came close to the customer not to initiate the order taking routine, in which case the customer would have been required to respond to the ginger slices, but only 
to serve this food item. Therefore, the ginger slides obtained two different meanings: The first factual meaning was as a food item, which is unrelated to the ordering routine, and the second performative meaning was as a material object used to initiate the routine. These double meanings are necessary for routine initiation. The chefs needed to be equipped with various material resources that gave them an "excuse," in a sense, to position their bodies close to the customers. As an excuse, the material artifacts must be factually unrelated to the focal routine. In a service context such as sushi bars, plates and glasses are particularly useful because they are placed in the customer's vicinity. Putting ginger slices on a plate, wiping a plate, serving food and drinks, and removing empty plates and glasses are all useful excuses. Customers are not required to react to these actions. Therefore, it is critical where and how these material resources are placed in relation to the actors. Such a sociomaterial assemblage allows the routine to begin performatively.

In addition to material objects, bodies also work in a similar manner. The chefs were moving their bodies while engaged in other activities, e.g., opening a case, while performatively creating the interactional formation (Kendon, 1990) in which the routine performance could subsequently begin. The position and direction of the upper body was critical. Once the chefs created a sociomaterial assemblage where their upper bodies were facing a customer and they were sufficiently close to him or her, they could initiate the routine. Bodies are therefore effectively used to maintain multiple involvements in an ambiguous manner. Chefs could maintain multiple involvements at the same time by dividing body parts for each involvement (Schegloff, 1998); for instance, a chef maintained the body position and posture for making sushi while directing his face towards a customer. The subtle shifts of gaze to and away from a customer were shown to be effective. The direct gaze alone cannot achieve the alignment, and more indirect and ambivalent gazes were needed to allow parties the time and room by which they can align their actions to the routine performance. Occasional glances are effective means to show that a chef is still attentive to a customer, who might respond anytime, in a looselycoupled manner.

In sum, the contribution of this study is to clarify the importance of materiality that appears to be unrelated to the focal routine. D'Adderio (2008, p. 774) wrote, material artifacts "tend to sink in and become part of the users' habitual background" (emphasis in original). Yet, this materiality in background has not been fully examined. Scholars in routine dynamics have focused on artifactual representations such as rules, procedures, and tools that are clearly relevant to the routine although their meanings can be varied (Aroles and McLean, 2016; D'Adderio, 2011; 2014; Glaser, 2017); nobody doubts the relevance of rules and procedures for the routine, for instance. In contrast, the present study has shown that some artifacts were seemingly unrelated to the routine while in reality performatively consequential for it. In fact, we argue that these artifacts are required to be unrelated to the routine in order to help the routine initiate itself.

Finally, the concept of materiality is invoked not simply to highlight the importance of material environment; it is based on the larger critique of sovereign human subjects in modernist thought. Agency does not lie in a single human subject but rather is stretched across various heterogeneous elements including nonhumans (D'Adderio, 2008; 2011). The analysis shows that actions by the chef are made possible and relevant by the assemblage at that particular moment and this assemblage is reflexively constructed by the actions that it enables. Consequently, recognition is not cognitive but sociomaterial. We need to understand routine recognition in terms of an assemblage that cannot be reduced to any human subjects. Recognition is stretched across material objects and bodies as well as human actions. The professional skills necessary for achieving ostensive patterning of routines (Spee et al., 2016) are therefore embodied in this manner; these skills do not totally reside inside the subjects but are stretched across the assemblage.

\section{Recognizability through Sequential Actions}

These findings confirm the results of previous studies showing that routine performances are sequentially organized (Pentland et al., 2012). Particularly, LeBaron et al. (2016) have shown that the performance of patient hand-off routines at an intensive care unit achieved sharing of sufficient amount of information in an efficient manner by flexibly coordinating actions. First, they showed that participants used the ostensive sequence of moves within the routine as a resource. For instance, a physician skipped a certain move to highlight the importance of particular information. Second, physicians typically used the point of transition from one move to the next to negotiate the sufficiency or insufficiency of the information, remedying at that point if more discussion was needed. In all these 
cases, bodies and material objects were shown to be coordinated. Our findings support this insight by showing that the chef and the customer were orienting to the issue of whether they could proceed in the routine or wait for a while.

Our findings add to the prior studies by revealing that the coordination was not closed within a single routine, using only the sequence of that particular routine performance. The routine performance used performances of other routines to coordinate and align actions. Likewise, while LeBaron et al. (2016) showed the use of material objects such as a notebook, we add that material objects and bodies that appear to be unrelated to the focal routine is critical. The notebook was explicitly relevant to the handoff routine because it is where information pertinent to the patients was to be recorded. In contrast, we showed that the fact that material objects were unrelated to the focal routine was consequential for the coordination of actions.

That said, a question remains as to why the methods of using seemingly unrelated routines and materiality were not found in LeBaron et al. (2016). We want to direct attention to what LeBaron et al. have left out of the analysis. They showed that handoff routines usually took place within "a small meeting room" (p. 517), which is also called a "handoff room" (p. 518). They reported as an exception one case in which the room was occupied and the physicians had to perform the handoff while standing in the nursing station. If we include this meeting room in the assemblage, we can see that the performance of the handoff routine included the act of creating a space in the hospital demarcated from other routines. This implies that the routine performance was in fact interrelated to performances of other routines, yet some work was needed to suppress this interrelation. Only after the recognizability is achieved through such work, can we analyze the routine independently. It would be interesting to analyze the case where the handoff took place in the nursing station by examining other things that may comprise the material assemblage surrounding the handoff.

\section{Reflexive Openness of Routine Performances}

These findings suggest that we need to conceive routines as inherently open. The boundary of the routine is achieved through its relationship with performances of other routines, both through explicit switching to and from these other routine performances and through peripheral attention to them. This openness is doubly reflexive. First, we use what is happening outside the routine in order to perform the focal routine, particularly to achieve the recognizability. What happens outside the routine is not only a contingency to guard from-so that the routine can unfold safely-but also a resource for the achievement of the routine performance. That is to say, we reflexively use the openness in order to perform a routine. Second, we keep this openness implicit by rendering other routine performances unrelated to the focal one and presenting the focal routine as closed from other routine performances. That is to say, we not only use the openness to achieve the routine performance but also make this use of the openness implicit.

The most seemingly closed routine performances are also open. We can consider the prototypical case of the airline check-in counter. As a seemingly clear-cut act of beginning a routine performance, an employee at the counter calls, "Next in line?" The first person in the line comes to the counter and the check-in routine starts. This explicit call may appear to initiate the routine performance unproblematically without any reference of what is happening outside the routine. In this case, however, it is important that people are already waiting in line. This material configuration is part of the check-in routine at the counter. Because it is typically designed such that everyone can see the whole scene, those in the line orient to initiations of the check-in routine. If the first person does not move, others immediately prompt her to do so. If the employee does not call for a next customer while his station is open, then those in the line may well become confused and sometimes irritated if they have been waiting too long. The first person in line often starts to move before the call, observing that the previous customer is leaving. The monitoring of other routine performances through material configurations and bodily movements is critical for achieving the recognizability of the routine performance. In short, smooth initiation of the routine performance is in fact made smooth due to the tight coordination that is happening outside the actual routine of check-in.

Even when we see a recognizable pattern is established and a routine performance forms a coherent identity, we should not forget that it is open to other routine performances. An instructor's lecturing is a good example of a routine performance that is open to other ongoing activity. If a student speaks to another while the instructor is talking, an instructor might ask if the student has a question and then reiterate what the student might have missed. If students are not paying attention and the 
professor can see them using social media on phones or tablets, she may pause the lecture and remind the students to pay attention. Such side activities are not simply separated from the lecturing but in fact constitutive parts of it (Goffman, 1961). This can be seen again in the airline check-in counter. While an employee is serving a customer, what is happening elsewhere, e.g., other customers waiting in line, is relevant. The employee and the customer cannot waste too much time doing something that appears unrelated, e.g., enjoying an unrelated conversation. When the employee has to do something else than helping the customer, e.g., taking a phone call, she needs to show that it is an important part of her work and that there is a legitimate reason to keep customers waiting. Therefore, while they engage in the focal routine, they are also attentive to other activities.

\section{Boundary Conditions}

We inquired into the beginnings of routine performances, specifically by choosing a setting where the beginning is problematic. There are three important conditions under which the findings reported above can be generalizable. First, when a routine started, there were almost always a number of other ongoing activities occurring. A routine performance needs to take into account these activities and make itself recognizably separate from but at the same time related to these other activities. Second, multiple people interacted directly. The beginning of a routine is problematic when multiple participants who are engaged in various activities need to recognize the routine and align themselves to it. Third, the participants in the routine shared the same material space in which various artifacts and bodies were relevant.

In contrast, if a single person is initiating a routine performance without any presence of others, e.g., processing a request sent on a computer (Spee et al., 2016), changing towels at a hotel (Bapuji, Hora and Saeed, 2012), or collecting waste from households (Turner and Rindova, 2012; 2018), then the practices we have observed may not be salient. However, it is an empirical question whether the subtle practices are still observed in such a case. Even if a routine is initiated through a phone conversation, in which case participants do not share the same space, we already know that there are several material resources that are subtly consequential for the routine performance such as the phone's ring (Schegloff, 1968) and background sounds, e.g., typing on a keyboard (Whalen, 1995). In the context of the waste collection routine, Turner and Rindova (2018, p. 1271) discussed the effect of "the sound of the garbage truck" for triggering another routine by citing an example where "the arrival of a garbage truck is used as cue to wake up the grandkids." Therefore, even in situations where participants' actions are mediated, subtle and seemingly unrelated embodied and material actions may well be important.

On the other hand, people working relatively independently and communicating through documents or objects may not have such exigencies. In the case of hotel towel changing routines, the communication between the hotel and the guests is mediated by objects designating reuse or replace (Bapuji et al., 2012). The participants do not directly interact. Employees often have to guess whether the customer intends to reuse or replace the towel. This example is interesting because the recognizability is precisely at issue and much material work needs to be done to create a recognizable pattern of actions.

Similarly, Spee et al. (2016) described how insurance underwriters worked with documents and emails on a computer. These underwriters appear to clearly engage in routine performances when receiving emails that trigger certain work processes. Nonetheless, they must be embedded in a local sociomaterial workplace in which many different activities are and can be happening, e.g., interruption by a phone call. Interestingly, Spee et al. (2016) observed: "As a quick sense check, he asks Charles, a fellow U.S. property underwriter who is walking by" (p. 772). This kind of request-stopping or approaching somebody for assistance-often requires the type of practices that this study revealed, using seemingly unrelated actions and materiality (Yamauchi, 2015). We suspect that these kinds of interactions happen frequently. We should further note that a mediated request sent by email cannot easily initiate a routine performance. The underwriters face a number of different routine performances at the same time: "With 400 deals a year, many of them being appraised simultaneously" (Spee et al, 2016, p. 771). One does not simply start working on a request sent by email but needs to assess which of many requests should be started on first. An underwriter carefully crafted an email: "The more John [the underwriter] can communicate his judgment to Emily [who carries out modeling], the better she can customize her analysis. He therefore emails her his notes as a bullet-point list of instructions with a hyperlink to the modelable raw data from Ted's email" (p. 770, words in brackets 
added by the authors). Therefore, one cannot send a request at any time in any way; much prior work was done so that Emily's routine performance could quickly form a recognizable pattern.

In sum, although many of the practices that this study revealed may not be salient in other contexts where communication is less direct, we need to be open to an inquiry into how recognizability is achieved in such contexts. The present study sensitizes us to the possibility that one action alone cannot readily initiate a routine performance. This initiation requires much work, some of which may be seemingly unrelated to the routine performance itself.

\section{CONCLUSION}

This study revisited routine recognizability in light of two recent themes in routine dynamics, namely interrelatedness and materiality. A routine performance not only performs a given routine but also creates the recognizability of the routine it is performing. Without the latter, we fail to account for how actions are patterned qua routine. That is to say, it is not sufficient that actions are taken in a situated manner; these actions need to create the recognition that they are patterned so that they constitute a routine. This is the reason why Feldman and Pentland (2003) originally distinguished between ostensive and performance aspects and emphasized their inseparability. We need to begin our analysis with actions, which are not automatically part of a routine and instead performatively create the recognition that they constitute the routine (Feldman, 2016). We have shown that interactions with seemingly unrelated other routines and materiality were critical to achieve routine recognition. In conclusion, we argue that a routine does not exist on its own; if a routine appears to exist apart from other routines and materiality, this is precisely due to the recognizability achieved by means of these seemingly unrelated routines and materiality.

\section{ACKNOWLEDGEMENT}

The authors would like to thank Associate Editor Daniel Muzio and three anonymous reviewers for their insightful comments. This work was supported by JSPS KAKENHI Grant Number JP17K03875.

\section{REFERENCES}

Aroles, J., and McLean, C. (2016). 'Rethinking Stability and Change in the Study of Organizational Routines: Difference and Repetition in a Newspaper-Printing Factory'. Organization Science, 27, 535-550.

Bapuji, H., Hora, M., and Saeed, A. M. (2012). 'Intentions, Intermediaries, and Interaction: Examining the Emergence of Routines'. Journal of Management Studies, 49, 1586-1607.

Birnholtz, J. P., Cohen, M. D., and Hoch, S. V. (2007). 'Organizational Character: On the Regeneration of Camp Poplar Grove'. Organization Science, 18, 315-332.

Callon, M. (1998). 'An essay on framing and overflowing: economic externalities revisited by sociology'. In Callon, M. (Ed.), Laws of the Markets. Oxford: Wiley-Blackwell.

Callon, M. (2013). 'Qu'est-ce qu'un agencement marchand?'. In Callon, M. (Ed.), Sociologie des Agencements Marchands. Paris.

Clark, C., and Pinch, T. (2010). 'Some major organisational consequences of some "minor," organised conduct: evidence from a video analysis of pre-verbal service encounters in a showroom retail store'. In Llewellyn, N. and Hindmarsh, J. (Eds), Organisation, Interaction and Practice. Cambridge: Cambridge University Press.

D'Adderio, L. (2008). 'The performativity of routines: Theorising the influence of artefacts and distributed agencies on routines dynamics'. Research Policy, 37, 769-789.

D'Adderio, L. (2011). 'Artifacts at the centre of routines: Performing the material turn in routines theory'. Journal of Institutional Economics, 7, 197-230.

D'Adderio, L. (2014). 'The Replication Dilemma Unravelled: How Organizations Enact Multiple Goals in Routine Transfer'. Organization Science, 25, 1325-1350.

Deleuze, G., and Guattari, F. (2013). A Thousand Plateaus. (B. Massumi, Trans.). London: Bloomsbury.

Emirbayer, M., and Mische, A. (1998). 'What Is Agency?'. The American Journal of Sociology, 103, 9621023.

Feldman, M. (2000). 'Organizational routines as a source of continuous change'. Organization Science, 11, 611-629.

Feldman, M. S. (2016). 'Routines as Process Past, Present, and Future'. In Howard-Grenville, J., Rerup, 
C., Langley, A., and Tsoukas, H. (Eds), Organizational Routines. Oxford: Oxford University Press.

Feldman, M., and Pentland, B. (2003). 'Reconceptualizing organizational routines as a source of flexibility and change'. Administrative Science Quarterly, 48, 94-118.

Garfinkel, H. (1967). Studies in Ethnomethodology. Cambridge, UK: Polity.

Glaser, V. L. (2017). 'Design Performances: How Organizations Inscribe Artifacts to Change Routines'. Academy of Management Journal, 60, 2126-2154.

Glaser, V. L., Fiss, P. C., and Kennedy, M. T. (2016). 'Making Snowflakes Like Stocks: Stretching, Bending, and Positioning to Make Financial Market Analogies Work in Online Advertising'. Organization Science, 27, 1029-1048.

Goffman, E. (1961). Behavior in Public Places. New York: The Free Press.

Goffman, E. (1981). Forms of Talk. Philadelphia: Univ of Pennsylvania Press.

Goodwin, C. (1980). 'Restarts, Pauses, and the Achievement of a State of Mutual Gaze at TurnBeginning'. Sociological Inquiry, 50, 272-302.

Haddington, P., Keisanen, T., Mondada, L., and Nevile, M. (Eds) (2014). Multiactivity in Social Interaction. Amsterdam: John Benjamins Publishing Company.

Heath, C. (1984). 'Participation in the medical consultation: the co-ordination of verbal and nonverbal behaviour between the doctor and patient'. Sociology of Health \& Illness, 6, 311-388.

Heath, C., Hindmarsh, J., and Luff, P. (2010). Video in Qualitative Research. Los Angeles: Sage Publications Ltd.

Heritage, J. (1984). Garfinkel and Ethnomethodology. Cambridge, UK: Polity.

Heritage, J. (1984). 'A change-of state token and asqects of its sequential piacement'. In Atkinson, J. M. and Heritage, J. (Eds), Structure of Social Action Studies in Conversation Analysis. Cambridge: Cambridge University Press.

Hindmarsh, J., and Llewellyn, N. (2017). 'Video in Sociomaterial Investigations:'. Organizational Research Methods, 19, 412-437.

Hindmarsh, J., and Pilnick, A. (2007). 'Knowing bodies at work: Embodiment and ephemeral teamwork in anaesthesia'. Organization Studies, 28, 1395-1416.

Howard-Grenville, J. A. (2005). 'The persistence of flexible organizational routines: The role of agency and organizational context'. Organization Science, 16, 618-636.

Kendon, A. (1990). Conducting Interaction. Cambridge: Cambridge University Press.

Kremser, W., and Schreyögg, G. (2016). 'The Dynamics of Interrelated Routines: Introducing the Cluster Level'. Organization Science, 27, 698-721.

Latour, B. (2005). Reassembling the Social: an Introduction to Actor-Network-Theory. Oxford University Press, USA.

LeBaron, C., Christianson, M. K., Garrett, L., and Ilan, R. (2016). 'Coordinating Flexible Performance During Everyday Work: An Ethnomethodological Study of Handoff Routines'. Organization Science, 27, 514-534.

Leidner, R. (1993). Fast Food, Fast Talk. Berkeley: University of California Press.

Llewellyn, N., and Hindmarsh, J. (Eds) (2010). Organisation, Interaction and Practice. Cambridge: Cambridge University Press.

Mondada, L. (2009). 'Emergent focused interactions in public places: A systematic analysis of the multimodal achievement of a common interactional space'. Journal of Pragmatics, 41, 1977-1997.

Orlikowski, W. J., and Scott, S. V. (2008). 'Sociomateriality: Challenging the separation of technology, work and organization'. The Academy of Management Annals, 2, 433-474.

Pentland, B. (1995). 'Grammatical Models of Organizational Processes'. Organization Science, 6, 541556.

Pentland, B. T., and Feldman, M. S. (2007). 'Narrative networks: Patterns of technology and organization'. Organization Science, 18, 781-795.

Pentland, B. T., and Feldman, M. S. (2008). 'Designing routines: On the folly of designing artifacts, while hoping for patterns of action'. Information and Organization, 18, 235-250.

Pentland, B. T., Feldman, M. S., Becker, M. C., and Liu, P. (2012). 'Dynamics of organizational routines: A generative model'. Journal of Management Studies, 49, 1484-1508.

Pentland, B., and Rueter, H. H. (1994). 'Organizational Routines as Grammars of Action'. Administrative Science Quarterly, 39, 484-510.

Schegloff, E. A. (1968). 'Sequencing in Conversational Openings'. American Anthropologist, 70, 10751095. 
Schegloff, E. A. (1986). 'The Routine as Achievement'. Human Studies, 9, 111-151.

Schegloff, E. A. (1998). 'Body torque'. Social Research, 65, 535-596.

Schegloff, E. A. (2007). Sequence Organization in Interaction: Volume 1: A Primer in Conversation Analysis. New York: Cambridge University Press.

Sele, K., and Grand, S. (2016). 'Unpacking the Dynamics of Ecologies of Routines: Mediators and Their Generative Effects in Routine Interactions'. Organization Science, 27, 722-738.

Spee, P., Jarzabkowski, P., and Smets, M. (2016). 'The Influence of Routine Interdependence and Skillful Accomplishment on the Coordination of Standardizing and Customizing'. Organization Science, 27, 759-781.

Turner, S. F., and Rindova, V. (2012). 'A Balancing act: How organizations pursue consistency in routine functioning in the face of ongoing change'. Organization Science, 23, 24-46.

Turner, S. F., and Rindova, V. P. (2018). 'Watching the clock: Action timing, patterning, and routine performance'. Academy of Management Journal, 61, 1253-1280.

Whalen, J. (1995). 'A technology of order production: computer-aided dispatch in public safety communication'. In Psathas, G. and ten Have, P. (Eds), Situated Order. Lanham, Md: University Press of America.

Yamauchi, Y. (2015). 'Reflexive Organizing for Knowledge Sharing: An Ethnomethodological Study of Service Technicians'. Journal of Management Studies, 52, 742-765.

Yamauchi, Y., and Hiramoto, T. (2016). 'Reflexivity of Routines: An Ethnomethodological Investigation of Initial Service Encounters at Sushi Bars in Tokyo'. Organization Studies, 37, 1473-1499.

Zbaracki, M. J., and Bergen, M. (2010). 'When truces collapse: A longitudinal study of price-adjustment routines'. Organization Science, 21, 955-972.

\section{APPENDIX TRANSCRIPTION SYSTEM}

\begin{tabular}{|l|l|}
\hline Symbols & \\
\hline[ & Point of overlap onset \\
\hline$]$ & Point of overlap outset \\
\hline$=$ & Connecting two lines represent no discernible silence between the lines \\
\hline$(1.2)$ & Pause in seconds. \\
\hline$()$. & Hearable but not readily measurable short silence (less than $0.2 \mathrm{sec}$ ) \\
\hline. & Falling intonation contour, not necessarily the end of a sentence \\
\hline, & Low rising intonation contour, not necessarily a clause boundary \\
\hline$?$ & High rising intonation contour \\
\hline$:$ & Stretched voice \\
\hline$\underline{\text { Word }}$ & Stressed talk \\
\hline${ }_{0}{ }^{\prime}$ & Relatively quieter voice \\
\hline- & A hyphen denotes a cut-off \\
\hline$><$ & Relatively rushed or compressed talk \\
\hline$<>$ & Markedly slow talk \\
\hline$($ word $)$ & Parentheses around a phrase denote the transcriber's guess at what might be said. \\
\hline$\uparrow$ & Rising intonation shift \\
\hline $\mathrm{h}$ & Exhaling \\
\hline. $\mathrm{h}$ & Inhaling \\
\hline
\end{tabular}

